NBER WORKING PAPER SERIES

\title{
CLIMATE CHANGE AND ECONOMIC GROWTH: EVIDENCE FROM THE LAST HALF CENTURY
}

\author{
Melissa Dell \\ Benjamin F. Jones \\ Benjamin A. Olken \\ Working Paper 14132 \\ http://www.nber.org/papers/w14132 \\ NATIONAL BUREAU OF ECONOMIC RESEARCH \\ 1050 Massachusetts Avenue \\ Cambridge, MA 02138 \\ June 2008
}

We thank Daron Acemoglu, Esther Duflo, Michael Greenstone, Jonathan Gruber, Seema Jayachandran, Charles Jones, Peter Klenow, William Nordhaus, Elias Papaioannou, and Carl Wunsch for helpful comments and suggestions. The views expressed herein are those of the author(s) and do not necessarily reflect the views of the National Bureau of Economic Research.

NBER working papers are circulated for discussion and comment purposes. They have not been peerreviewed or been subject to the review by the NBER Board of Directors that accompanies official NBER publications.

(C) 2008 by Melissa Dell, Benjamin F. Jones, and Benjamin A. Olken. All rights reserved. Short sections of text, not to exceed two paragraphs, may be quoted without explicit permission provided that full credit, including $\odot$ notice, is given to the source. 
Climate Change and Economic Growth: Evidence from the Last Half Century

Melissa Dell, Benjamin F. Jones, and Benjamin A. Olken

NBER Working Paper No. 14132

June 2008

JEL No. O11,O13,O40,Q54

\begin{abstract}
$\underline{\text { ABSTRACT }}$
This paper uses annual variation in temperature and precipitation over the past 50 years to examine the impact of climatic changes on economic activity throughout the world. We find three primary results. First, higher temperatures substantially reduce economic growth in poor countries but have little effect in rich countries. Second, higher temperatures appear to reduce growth rates in poor countries, rather than just the level of output. Third, higher temperatures have wide-ranging effects in poor nations, reducing agricultural output, industrial output, and aggregate investment, and increasing political instability. Analysis of decade or longer climate shifts also shows substantial negative effects on growth in poor countries. Should future impacts of climate change mirror these historical effects, the negative impact on poor countries may be substantial.
\end{abstract}

\author{
Melissa Dell \\ Department of Economics \\ Benjamin A. Olken \\ Harvard Society of Fellows \\ Massachusetts Institute of Technology \\ 78 Mt. Auburn St. \\ 50 Memorial Drive, Cambridge MA 02142 \\ mdell@mit.edu \\ Cambridge, MA 02138 \\ and NBER \\ Benjamin F. Jones \\ bolken@nber.org \\ Northwestern University \\ Kellogg School of Management \\ Department of Management and Strategy \\ 2001 Sheridan Road \\ Evanston, IL 60208 \\ and NBER \\ bjones@kellogg.northwestern.edu
}




\section{Introduction}

Climate change may - or may not - be a central issue for the world economy. Yet assessing the economic impact of climate change faces a fundamental challenge of complexity: the set of mechanisms through which climate may influence economic outcomes, positively or negatively, is extremely large and difficult to investigate comprehensively. Even if the effect of climate on each relevant mechanism were known, one would still be faced with the challenge of how various mechanisms interact to shape macroeconomic outcomes.

The complexity of the climate-economy relationship is apparent in a brief survey of the literature. Much research focuses on agriculture (e.g., Adams et al. 1990; Mendelsohn et al. 2001; Deschenes and Greenstone 2007; Guiteras 2007). Other research examines ocean fisheries, fresh water access, storm frequency, migration, tourism and many other potential issues, as reviewed extensively in the recent Intergovernmental Panel on Climate Change $4^{\text {th }}$ Assessment Report (IPCC 2007). Less discussed, but perhaps critical, are classic ideas in economic development that link productivity to temperature (e.g., Montesquieu 1750; Marshall 1890; Huntington 1915). Meanwhile, there are well-established, substantial effects of temperature on mortality (e.g. Curriero et al. 2002; Deschenes and Moretti 2007; Deschenes and Greenstone 2007), temperature on crime (e.g. Field 1992; Jacob et al. 2007), and drought on conflict (Miguel et al. 2004), all of which have direct and indirect effects on economic activity. Faced with these different channels, the traditional approach to estimating the overall economic impact of climate change is to use "Integrated Assessment Models" (IAM), which take some subset of mechanisms, specify their effects, and then add them up (e.g. Mendelsohn et al. 2000, Nordhaus 
and Boyer 2000, Tol 2002). Implementations of the IAM approach require many assumptions about which effects to include, how each operates, and how they aggregate. ${ }^{1}$

This paper takes a different approach. Rather than identifying mechanisms one-by-one and summing up, we examine the effects of temperature and precipitation on a single aggregate measure: economic growth. Specifically, we construct historical temperature and precipitation data for each country and year in the world from 1950 to 2003 and combine this dataset with historical growth data. The main identification strategy uses year-to-year fluctuations in temperature and precipitation within countries to estimate the impact of temperature and precipitation on economic growth. ${ }^{2}$ This approach estimates the effect of short-run climate fluctuations using relatively few assumptions. It examines aggregated outcomes directly, rather than relying on a priori assumptions about what mechanisms to include and how they might operate, interact, and aggregate.

Our main results show large, negative effects of higher temperatures on growth, but only in poor countries. In poorer countries, we estimate that a $1^{\circ} \mathrm{C}$ rise in temperature in a given year reduces economic growth in that year by about 1.1 percentage points. In rich countries, changes in temperature have no discernable effect on growth. Changes in precipitation also have no substantial effects on growth in either poor or rich countries. We find broadly consistent results across a wide range of alternative specifications.

\footnotetext{
${ }^{1}$ As a result of these many assumptions, even primary users of these models acknowledge their substantial limitations. For example, the Stern report (2007) describes IAM models as follows (p. 145):

"Making such estimates is a formidable task in many ways (discussed below). It is also a computationally demanding exercise, with the result that such models must make drastic, often heroic, simplifications along all stages of the climate-change chain. What is more, large uncertainties are associated with each element in the cycle. Nevertheless, the IAMs remain the best tool available for estimating aggregate quantitative global costs and risks of climate change."

${ }^{2}$ The use of annual variation in temperature and precipitation to estimate the impact of climate change was pioneered by Deschenes and Greenstone (2007), who use annual county-level data in the United States to estimate the impact of climate on U.S. agricultural output.
} 
To interpret these effects, one can distinguish two potential ways temperature could affect economic activity: 1) influencing the level of output, for example by affecting agricultural yields, or 2) influencing an economy's ability to grow, for example by affecting investments or institutions that influence productivity growth. By looking at multiple lags of temperature, we can examine whether temperature shocks appear to have temporary or persistent impacts on economic output - and thus whether temperature has level or growth effects (or both). Our results suggest that higher temperatures may reduce the growth rate in poor countries, not simply the level of output. Since even small growth effects have large consequences over time, these growth effects - if they persist in the medium run - would imply large impacts of temperature increases.

We also find evidence for a broad set of mechanisms through which temperature might affect growth in poor countries. While agricultural output contractions are part of the story, we also find adverse effects of hot years on industrial output and aggregate investment. Further, higher temperatures lead to political instability in poor countries, as evidenced by irregular changes in the national leadership. These industry, investment, and institutional effects sit outside the primarily agricultural focus of most economic research on climate change and underscore the importance of an inclusive approach to understanding climate change implications. These broader mechanisms also help explain how temperature might affect growth rates in poor countries, not simply the level of output.

These results are identified using short-run fluctuations in temperature and precipitation. A fundamental issue, however, is that the long-run effects of climate change may be quite different from the effects of short-run fluctuations. For example, in the long run, adaptation mechanisms might mitigate the short-run economic impacts that we observe. Alternatively, 
climate change may have additional long-run effects, including changes in water tables, soil quality, and sea level, producing larger impacts (IPCC, 2007; Meehl et al., 2004; Nicholls and Leatherman, 1995).

Although our approach (like others) cannot fully overcome these challenges, we can make further headway by examining longer-term climate shifts. Mean global land temperatures have risen nearly $1^{\circ} \mathrm{C}$ since 1970 (Brohan et al. 2006), but countries have not warmed equally. We therefore examine whether those countries that experienced the largest climate shifts between early and late periods in our sample had the largest shifts in their growth rates. Though this approach has less statistical power than using annual variation, the estimated effects of increased temperature in poor countries over decade or longer time horizons are very similar to our panel estimates. Should there be rapid adaptation to climate change, these estimates also appear consistent with the overall cross-sectional relationship between temperature and percapita GDP found in the world today. To the extent that these historical effects continue, our estimates suggest substantial negative consequences of climate change for poor countries and few effects on rich countries.

The remainder of the paper is organized as follows. Section 2 introduces the data and provides descriptive statistics. Section 3 describes the estimation strategy, presents the main results, and considers a number of robustness checks. Section 4 considers channels that may link climate change to national output. Section 5 estimates the effects of longer-run climate shifts, offers projected implications of climate change using a standard climate model, and discusses the limitations of such predictions. Section 6 concludes. 


\section{Data and Descriptive Statistics}

\subsection{Data}

The historical climate data is taken from the Terrestrial Air Temperature and

Precipitation: 1900-2006 Gridded Monthly Time Series, Version 1.01 (Matsuura and Willmott 2007). This data set provides worldwide (terrestrial) monthly mean temperature and precipitation data at $0.5 \times 0.5$ degree resolution (approximately $56 \mathrm{~km} \times 56 \mathrm{~km}$ at the equator). Values are interpolated for each grid node from an average of 20 different weather stations, with corrections for elevation.

We use geospatial software to aggregate the climate data to the country-year level. Our main specifications use population-weighted average temperature and precipitation, where the weights are constructed from 1990 population data at 30 arc second resolution (approximately $1 \mathrm{~km}$ at the equator) from the Global Rural-Urban Mapping Project (Balk et al. 2004). We also consider averaging based on geographic area, which produces broadly similar climate variables for most countries. ${ }^{3}$ Appendix I presents additional details about the climate data.

For economic data, we primarily use the Penn World Tables Version 6.2 (Heston et al. 2006). We also use data from the World Development Indicators (World Bank 2007) to examine robustness and disaggregated value-added output from agriculture and industry. We focus on the panel of 136 countries with at least 20 years of GDP data in the Penn World Tables, and consider other samples as robustness checks.

\subsection{Descriptive statistics}

Figure 1 presents population-weighted global mean temperature and precipitation from 1950 to 2006 . The figure shows that the world has become about $1{ }^{\circ} \mathrm{C}$ warmer since the early

\footnotetext{
${ }^{3}$ Countries where the weighting scheme makes a substantial difference are those with large, sparsely populated areas with unusual climates: Russia (Siberia), Canada (the arctic and sub-arctic areas), the United States (Alaska), and Australia (central Australia).
} 
1970s, and that average precipitation has fallen by about $10 \mathrm{~cm}$. The warming trend since the 1970s is well-documented (e.g. Brohan et al. 2006) and suggests a linear rate of change that, should it continue, would predict an additional $3^{\circ} \mathrm{C}$ warming by 2100 , in line with many climate models. The decline in precipitation is also well-documented, though this trend stands in contrast to most climate models, which predict that global warming will come with increased precipitation on average. ${ }^{4}$

To examine variation in climate, Figure 2 summarizes temperature (left graph) and precipitation (right graph) data for each country in the sample, plotted against log per-capita PPP GDP in the year 2000. For each country, the circle symbols represent the mean levels of temperature and precipitation in the first decade of our sample (1950-1959), the plus symbols represent the mean levels in the last decade of our sample (1996-2005), and the gray lines indicate the range of annual mean levels we observe for that country.

The left panel of Figure 2 shows the tremendous temperature variation across countries: the hottest country in the world is Mauritania, with an average population-weighted temperature of $28.4{ }^{\circ} \mathrm{C}$, and the coldest is Mongolia, with an average population-weighted temperature of $-1.77^{\circ} \mathrm{C}$. Figure 2 also shows the strong relationship between temperature and per-capita income, with hot countries tending to be poor and cold countries rich. This relationship has been known since at least the $18^{\text {th }}$ century (Montesquieu 1750) and has been further established using subnational data (Nordhaus 2006). The exceptions to this rule fall into two main groups: oil states of the Middle East, such as Qatar and Kuwait, which are hot and wealthy, and Communist / postCommunist states, such as Mongolia and North Korea, which are cold and poor.

\footnotetext{
${ }^{4}$ Historical area-weighted data for land shows a precipitation increase of nearly $1 \mathrm{~cm}$ over the $20^{\text {th }}$ century. However, a peak occurred in the 1950s, with precipitation falling across more recent decades (Neng et al., 2002; New et al., 2001). On average, climate projections predict a rise in precipitation equal to about half of the recent global decrease by the end of the $21^{\text {st }}$ century (see IPCC 2007 Working Group 1 Chapter 10).
} 
Looking at variability within countries, we see fluctuations in annual mean temperatures on the order of about $2-3^{\circ} \mathrm{C}$. Thus, the max-min variation within countries is more than twice the average increase in temperature observed over the period, and similar to the increase in global temperatures expected to occur over the next century. Figure 2 further shows that, while there tend to be larger temperature fluctuations in cooler countries, the upward trend in temperature has occurred globally with similar magnitude in both hot and cold countries.

Examining the data on precipitation in the right panel of Figure 2 shows substantial annual variability in precipitation in all but the very driest countries. However, there is no clear relationship between the level of precipitation and the level of per-capita income in 2000.

To examine the variability further, Table 1 documents the extent of temperature and precipitation fluctuations within countries. While the max-min difference in temperature is about $2-3^{\circ} \mathrm{C}$ (Figure 2), a country's temperature deviates more than $1^{\circ} \mathrm{C}$ from the country mean approximately once every fifteen years. Precipitation is more volatile, with deviations from mean rainfall of about $400-500 \mathrm{~mm}$ appearing once every fifteen years. When common global or region-specific year fixed effects are removed, these deviations become somewhat more modest. 


\section{The effect of climate fluctuations on economic activity}

In this section we develop the empirical framework for the analysis of climate shocks, present our main results, and consider a variety of robustness checks.

\subsection{Empirical framework}

Our empirical framework follows the derivation in Bond et al. (2007). To fix ideas, consider the following simple economy: ${ }^{5}$

$$
\begin{aligned}
& Y_{i t}=e^{\beta T_{i t}} A_{i t} L_{i t} \\
& \Delta A_{i t} / A_{i t}=g_{i}+\gamma T_{i t}
\end{aligned}
$$

where $Y$ is aggregate output, $L$ measures population, $A$ measures labor productivity, and $T$ measures climate. Equation (1) captures the level effect of climate on production; e.g. the effect of current temperature or precipitation on crop yields. Equation (2) captures the growth effect of climate; e.g. the effect of climate on features such as institutions that influence productivity growth.

Taking logs in the production function and differencing with respect to time, we have the dynamic growth equation

$$
g_{i t}=g_{i}+(\beta+\gamma) T_{i t}-\beta T_{i t-1}
$$

where $g_{i t}$ is the growth rate of per-capita output. The "level effects" of climate shocks on output, which come from equation (1), appear through $\beta$. The "growth effects" of climate shocks, which come from equation (2), appear through $\gamma \cdot{ }^{6}$

\footnotetext{
${ }^{5}$ We focus here on this simple production model. Appendix II extends the reasoning developed here to more general dynamic panel models that incorporate richer lag structures and lagged dependent variables.

${ }^{6}$ Rather than first-differencing (1), one could integrate (2), producing a fully-specified equation in the log level of output. However, as Bond et al. (2007) notes, this creates non-stationarity in both output levels (on the left-hand side) and accumulable factors (on the right-hand side). To avoid relying on cointegration assumptions for identification, Bond et al recommend first-differencing.
} 
The growth equation in (3) allows separate identification of level effects and growth effects through the examination of transitory weather shocks. In particular, both effects influence the growth rate in the initial period of the shock. The difference is that the level effect eventually reverses itself as the climate returns to its prior state. For example, a temperature shock may reduce agricultural yields, but once temperature returns to its average value, agricultural yields bounce back. By contrast, the growth effect appears during the climate shock and is not reversed: a failure to innovate in one period leaves the country permanently further behind. The growth effect is identified in (3) as the summation of the climate effects over time.

The above reasoning extends to models where climate effects play out more slowly. ${ }^{7}$ With more general lag structures in (1) and (2), the growth effect is still identified by summing the lagged effects of the climate shock. This standard distributed-lag result is demonstrated formally in Appendix II.

To estimate these effects, we run panel regressions of the form

$$
g_{i t}=\theta_{i}+\theta_{r t}+\sum_{j=0}^{L} \rho_{j} T_{i t-j}+\varepsilon_{i t}
$$

where $\theta_{i}$ are country fixed effects, $\theta_{r t}$ are time fixed effects (interacted separately with region dummies and a poor country dummy in our main specifications), $\varepsilon_{i t}$ is an error term clustered by country, and $T_{i t}$ is a vector of climate variables (temperature and precipitation) with up to $L$ lags included. In addition, we also consider variations of (4) that include interactions between climate variables and country characteristics. We have verified using Monte Carlo analysis that the

\footnotetext{
${ }^{7}$ For example, low temperatures in the latter part of one year could affect harvests the next year - which would generate a lagged level effect. Alternatively, a permanent shock to productivity could influence subsequent capital accumulation as the capital stock adjusted to its new steady state - which would generate a lagged growth effect. The key distinction is that, as in equation (3), level effects eventually generate equal and opposite responses through further lags, whereas growth effects do not. See Appendix II.
} 
specification in (4) produces unbiased estimates of both growth and level effects and has appropriate size given the properties of our data. (See Appendix II for more details.)

We begin by estimating (4) with no lags, focusing on the null hypothesis that climate does not affect growth:

$$
H_{0}(L=0): \rho_{0}=0
$$

A failure to reject this hypothesis would indicate an absence of both level and growth effects. In subsequent regressions with lags, following the conventions in the distributed-lag literature (see Greene 2000), we separately test the immediate effect of temperature:

$$
H_{0}^{1}(L>0): \rho_{0}=0
$$

and the cumulated effect of temperature:

$$
H_{0}^{2}(L>0): \sum_{j=0}^{L} \rho_{j}=0
$$

The summation of the lag coefficients corresponds to the parameter $\gamma$, the growth effect, in the simple model above, as well as a more general concept of growth effects in models with longer lag structures, as demonstrated in Appendix II. Appendix II also discusses generalizations of the empirical model and tests following Bond et al. (2007) that allow for more general short-run dynamics. As discussed in the appendix, the results from the extended dynamic model are very similar to the results from the simpler model developed here.

\subsection{Panel results}

Table 2 examines the null hypothesis that climate does not affect growth, either through level effects or growth effects. It presents results from estimating equation (4) with no lags (i.e., imposing $\rho_{j}=0$ for all $j>0$; models with lags are examined in the next subsection). Column (1) of Table 2 shows a negative but statistically insignificant relationship between temperature fluctuations and growth. In column (2), we interact temperature with a dummy for a country 
being "poor", defined as having below-median PPP-adjusted per-capita GDP in the first year the country enters the dataset. The coefficient on the interaction between the "poor" dummy and temperature is negative and statistically significant, indicating substantial heterogeneity between poor and rich countries. ${ }^{8}$ As shown in the last row of the table (which reports the sum of the main effect of temperature and its interaction with the poor dummy), the net effect of a $1^{\circ} \mathrm{C}$ rise in temperature is to decrease growth rates in poor countries by -1.09 percentage points.

The next columns of Table 2 examine the impact of precipitation and do not show strong effects, in rich or poor countries. Focusing on column (4), an extra 100mm of annual precipitation is associated with a 0.07 percentage point lower growth rate in rich countries and a statistically insignificant 0.05 percentage point higher growth rate in poor countries. Since global mean precipitation levels have fallen nearly $100 \mathrm{~mm}$ in the last 50 years (see Figure 1), a $100 \mathrm{~mm}$ variation in precipitation is on the same order historically as the $1^{\circ} \mathrm{C}$ rise in temperature. By this metric, the precipitation effects typically appear at least a factor of 10 smaller than the temperature effect in poor countries. Moreover, Table 4 below shows that the statistical significance of the precipitation effects are sensitive to specification, suggesting that they should be interpreted with caution. Column (5) shows that controlling for temperature and precipitation simultaneously leaves both estimates unchanged.

Poorer countries tend to be both hotter and more agricultural. In columns (6) and (7) we consider whether being "poor" proxies for these characteristics. Column (6) adds the interaction between temperature and "hot", defined as having above median temperature in the 1950s. The negative effect of temperature appears through being poor, not through being hot, with the poor

\footnotetext{
${ }^{8}$ We have also considered quintiles of initial per-capita income rather than a binary distinction. We find the largest negative effects of temperature on the bottom 2 quintiles of temperature.
} 
coefficient remaining unchanged. ${ }^{9}$ Column (7) controls for the interaction between temperature and "agricultural", defined as having an above median agricultural GDP share in $1995 .{ }^{10}$ Once again, the negative effect of temperature appears through being poor. ${ }^{11}$ While it is impossible to definitively separate the impacts of poverty from those of the agriculture share or mean temperature, this evidence suggests that being poor characterizes a locus of substantial negative temperature effects.

\subsection{Models with lags}

The above results, using the simple model with no lags, reject the null hypothesis that temperature has no effect on growth in poor countries. This section considers more flexible models with up to 10 lags of temperature to better understand the dynamics of these temperature effects, nesting both the level and growth effects of temperature described in Section 3.1.

Table 3 presents results from estimating equation (4) with no lags, one lag, three lags, five lags, or ten lags of the climate variables. In columns (1) - (5), temperature and its lags are the only climate variables included. Columns (6) - (10) present results where precipitation and its lags are also included. All climate variables are interacted with poor and rich country dummies. The bottom two rows of each column present, separately, the cumulated effect of temperature for poor and rich countries, calculated by summing the respective temperature variable and its lags. In models with more than three lags, given space constraints, the table reports only the first three lags and the sum of all the lags.

\footnotetext{
${ }^{9}$ In results not reported in the table, we have also experimented with different definitions of "hot," such as being above the $75^{\text {th }}$ or $90^{\text {th }}$ percentiles of the world average temperature distribution, as well a linear temperature variable. The results from these alternative specifications are qualitatively similar to the results presented in the Table.

${ }^{10}$ We use 1995 data for agricultural share because data coverage from earlier years is sparse. Using earlier data cuts sample sizes considerably but produces broadly similar results.

${ }^{11}$ In results not reported in the table, regressions that control only for temperature fluctuations and their interaction with the agriculture share (i.e. not including interactions with national income) produce statistically insignificant effects for agriculture, further suggesting that poverty is the more informative characteristic. Furthermore, regressions that include linear interactions with initial income, temperature, and agriculture share (as opposed to binary dummies) continue to show that initial poverty is the relevant distinction.
} 
Table 3 shows that the cumulative effect of temperature in poor countries becomes more negative as more lags are included. With no lags, in columns (1) and (6), a one-time $1^{\circ} \mathrm{C}$ temperature increase in a poor country reduces growth by $1.07-1.09$ percentage points. With one lag included, the cumulative effect is a reduction of $1.28-1.30$ percentage points. Including three, five, or ten lags increases the magnitude and statistical significance of these cumulative effects, with a $1^{\circ} \mathrm{C}$ temperature increase producing a $1.58-2.01$ percentage point reduction in growth.

The individual lag coefficients show little evidence of a level effect of temperature on output. That is, the effects of above average temperature appear to persist in the medium-run, rather than being reversed. Recalling the empirical framework from Section 3.1, level effects are reversed when the climate shock is reversed. In the model with one lag - i.e., columns (2) and (6) - a level effect would appear as equal and opposite coefficients on the immediate effect and the first lag. More generally, even if level effects occur with lags - i.e., if last year's temperature affects this year's harvest - level effects are eventually reversed once the shock disappears. Therefore, to the extent temperature effects are level effects, the cumulated sum of the temperature effect and all its lags should be zero. That the lags in Table 3 do not sum to zero and, in fact, the cumulated effect of temperature becomes stronger as more lags are added suggests that the effects of temperature persist in the medium run; i.e., they look more like growth effects than level effects.

Of course, temperature effects may be mitigated beyond the 10-year horizon examined here. However, the increasing cumulative impact of temperature as longer lags are considered suggests that, if anything, the effects of temperature shocks strengthen over time rather than diminish. In Section 5.1, we consider an alternative empirical approach that examines longer-run 
historical relationships between changes in temperature and changes in growth. That analysis finds longer-run effects consistent with these panel results.

\subsection{Robustness}

Table 4 considers a variety of robustness checks. For each specification, Panel A reports the results from models with no lags (i.e., equivalent to column 5 of Table 2), Panel B reports cumulative effects from models with five lags (i.e., equivalent to the cumulative effects in column 9 of Table 3), and Panel C reports cumulative effects from models with ten lags (i.e., equivalent to the cumulative effects in column 10 of Table 3). Results from models with one and three lags are qualitatively similar and are omitted to conserve space. To facilitate comparisons, the relevant results from Tables 2 and 3 are repeated in the first column of Table 4 .

We find that the results are broadly consistent across a range of alternative specifications. Column (2) shows that including only country and region $\times$ year fixed effects (i.e., dropping the poor $\times$ year fixed effects) produces similar estimated temperature effects in poor countries. Similar results also emerge in column (3), which uses common global year fixed effects instead of region $\times$ year fixed effects, and column (4), which incorporates country-specific trends as well as region $\times$ year and poor $\times$ year fixed effects, though the standard errors increase in column (4) so that the five and ten lag results are no longer statistically significant. ${ }^{12}$

Column (5) shows that limiting the sample to 1971-2003, for which we have a balanced sample, strengthens the temperature effect in poor countries. Column (6) adds countries with less than 20 years of data, and continues to show substantial negative effects in poor countries. In this sample, the zero-lag model shows a positive effect of increased temperature in richer countries.

\footnotetext{
${ }^{12}$ In addition, we have also considered using logs rather than levels of annual average temperature and precipitation. This specification strengthens the results. We have also estimated a first differenced version of (4), i.e. $\Delta g_{i t}=\Delta \theta_{r t}+\sum_{j=0}^{L} \rho_{j} \Delta T_{i t-j}+\Delta \varepsilon_{i t}$. This produces very similar results for the 0 lag model, while the estimates become substantially more negative and more imprecise as we add additional lags.
} 
This effect is driven by several post-Soviet states, which are grouped as rich and which enter the data in the early 1990s, and appears to be driven by extreme outliers during the post-Communist transition. $^{13}$

Column (7) re-considers the main specification using growth data from the World Development Indicators rather than the Penn World Tables. The zero-lag and five-lag results are very similar using WDI data. The ten-lag result attenuates somewhat and is statistically insignificant. Column (8) uses climate data aggregated using area-weighting rather than population-weighting and shows similar effects. ${ }^{14}$ Finally, we split the sample into Sub-Saharan African countries (column 9) and all other countries (column 10). In the model with zero lags, the negative impacts of temperature are especially pronounced in Sub-Saharan Africa and much weaker elsewhere. However, when we examine either the five or ten lag models, the negative point estimates are similar and large (though statistically insignificant) in both samples. ${ }^{15}$

In our analysis, temperature enters linearly, whereas one might suspect that temperature has non-linear effects. ${ }^{16}$ To investigate this possibility, we examined more flexible aggregations of the sub-national temperature data. Using daily climate data available on a $1.0 \mathrm{x}$ 1.0 degree grid (NCC, 2005), we calculated the number of 'people-days' spent at each temperature and precipitation level throughout the year for each country. We then repeated the panel analysis above (e.g., equation (4) with no lags) allowing the climate effects to vary arbitrarily at different temperature and precipitation ranges. Unfortunately, we did not have

\footnotetext{
${ }^{13}$ Estimating the effect of temperature on growth for the sub-sample of post-Soviet / Eastern European countries shows that each $1^{\circ} \mathrm{C}$ is associated with 3.9 percentage points higher growth. However, when excluding the transition years 1992,1993 , and 1994 , each $1^{\circ} \mathrm{C}$ rise becomes associated with 0.62 percentage points lower growth. ${ }^{14}$ Weighting by rural population or urban population yields similar results to using total population weights. ${ }^{15}$ Another potential concern is that climate data quality may be lower for Africa. We have repeated our analysis of Africa with a number of (independently collected) alternative datasets - the Global Precipitation Climatology Project, the National Center for Environment Prediction, and the UN Food and Agricultural Organization Climatic Data. Results are very similar in all samples.

${ }^{16}$ For example, Deschenes and Greenstone (2007a, 2007b) find non-linear temperature effects for agriculture and mortality.
} 
sufficient power to tease out detailed effects of the distribution of days within different climate ranges. While the results are imprecise, the point estimates suggest that the impact of temperature on GDP is roughly linear, supporting the focus on annual averages (results available on request). ${ }^{17}$

\section{Channels}

The climate change literature suggests a wide array of channels through which climate may affect economic outcomes, from agriculture to political instability to health. In this section, we apply the panel methodology developed above to investigate several such mechanisms.

It is important to note that these analyses are reduced-form, and therefore do not identify the possibly complex structural relationships between climate, growth, and other outcomes. For example, higher temperature could lead directly to political instability by making a population more prone to riot, with possible effects on growth. Conversely higher temperature could cause lower agriculture yields, with the resulting GDP reduction leading to political instability. Teasing out structural relationships between these many variables would require a large number of identifying assumptions. Instead, we focus on net climate effects, documenting several plausible channels through which climate may affect aggregate output.

\subsection{Decomposing the impacts of climate}

Table 5 examines the impact of temperature and precipitation on several components of

GDP. Panel A begins with zero-lag models to test the null hypotheses of no effects of temperature and precipitation. Column (1) examines growth in agricultural value-added, and

\footnotetext{
${ }^{17}$ We have also conducted several exercises to look for nonlinear effects of the average temperature variable and found little evidence for non-linearities at that level as well. First, we verified that both hot and cold deviations from the national temperature mean have effects of similar absolute magnitude on growth. Second, we used median regressions to verify that the results are not driven by outliers. Third, we found that temperature shocks do not affect poor countries differentially depending on whether the country is typically hot or cold, though the tiny number of cold poor countries prevents a definitive conclusion on this dimension (results available on request).
} 
column (2) investigates growth in industrial value-added. ${ }^{18}$ These variables are taken from the World Development Indicators. (Note that the WDI sample is more limited than the PWT sample.) Column (3) examines growth in investment, using data from the Penn World Tables.

The results in Panel A show substantial, negative effects of temperature in poor countries on all three of these components of GDP. Column (1) shows that a $1^{\circ} \mathrm{C}$ higher temperature in poor countries is associated with 2.37 percentage points lower growth in agricultural output. For wealthier countries, the point estimate is substantially smaller and not statistically significant, showing 0.34 percentage points lower growth in agricultural output for each additional $1{ }^{\circ} \mathrm{C}$ of temperature. As might be expected, precipitation positively impacts agriculture - each additional $100 \mathrm{~mm}$ of annual rainfall is associated with 0.24 percentage points higher growth in agricultural output in poor countries and 0.14 percentage points higher growth in agricultural output in richer countries.

Column (2) of Panel A shows negative temperature impacts on the growth of industrial value-added in poor countries. Specifically, a $1^{\circ} \mathrm{C}$ higher temperature in poor countries is associated with 2.44 percentage points lower growth in industrial output. This effect may reflect labor productivity losses, consistent with a long literature documenting the impact of temperature on output in factory settings. ${ }^{19}$ Alternatively, this effect could represent a demand-side spillover from the negative effect of temperature on agricultural output.

\footnotetext{
${ }^{18}$ The residual category, services, is typically computed as the difference between total value-added and the sum of agricultural and industrial value added. As such, it is likely more noisily measured and, consistent with increased measurement error we find no statistically significant results when we examine services (results available on request).

${ }^{19}$ Building on classic ideas in economic development that link productivity to temperature (Montesquieu 1750; Marshall 1890), Huntington (1915) documented that high temperature reduces the productivity of piece-rate Connecticut factory workers and Florida cigar-makers. More recently, Link and Pepler (1970), Wyon (1976), Meese et al. (1982), and others have found substantial negative impacts of higher temperatures on the productivity of factory workers.
} 
The results on investment in column (3) also show substantial negative impacts of temperature in poor countries. Specifically, a $1^{\circ} \mathrm{C}$ higher temperature in poor countries reduces the growth rate of investment by 3 percentage points. We find no temperature effects in rich countries. $^{20}$

Panel B examines the lag structure of these effects. For each dependent variable (growth in agriculture, growth in industry, and growth in investment), we present results with 1,5 , and 10 lags. For all three dependent variables, the impact effect - i.e., the coefficient on contemporaneous temperature - is negative, large, and statistically significant. For agriculture and investment, the point estimates of the cumulative effects, while imprecise, are somewhat smaller than the immediate effects, suggesting the presence of some combination of growth and level effects for these variables. By contrast, for industrial value added, the point estimates of the cumulative effects are virtually identical to the immediate effect. ${ }^{21}$

Overall, the findings in Table 5 demonstrate broad negative effects of increased temperature. We find effects not only on agriculture, but also on industrial output and investment. The fact that temperature has such broad effects may help explain both the magnitude of the overall effect of temperature on output as well as its persistence.

\subsection{Political economy effects}

Temperature may also impact growth if increased temperature leads to political instability, which in turn impedes investment and productivity growth. The idea that riots and protests are more likely in warmer weather is an old idea that has found substantial empirical

\footnotetext{
${ }^{20}$ Note, however, that there is a significant precipitation effect in rich countries. Using daily data on precipitation (NCC, 2005), we find that having a larger number of days with very high precipitation has a significant negative effect on aggregate output in rich countries (results available upon request). One conjecture is that construction responds negatively to rain, providing the investment effect.

${ }^{21}$ There also is some evidence of cumulative effects of precipitation on agricultural output, particularly in rich countries. One potential explanation involves the effects of drought on soil erosion, which may have longer-run consequences. For example, Hornbeck (2007) documents that soil erosion during the Dust Bowl years in the United States had substantially negative and lasting consequences on agricultural output.
} 
support (e.g., United States Riot Commission, 1968; Carlsmith and Anderson, 1979;

Boyanowsky, 1999). ${ }^{22}$ If warm weather causes riots, in some fraction of cases these riots could spill over into political change and instability. Alternatively, economic shocks from climate might provoke dissatisfied citizens to seek institutional change.

We examine the impact of temperature on several measures of political instability. First, the Polity IV dataset (Marshall and Jaggers 2004) rates the political system in each country annually from -10 (fully autocratic) to +10 (fully democratic). This POLITY variable further designates "interregnum periods", which are years when the political system is in flux and no clear political regime has emerged. We consider two dummy variables: one for any change in the POLITY variable, indicating a political change, and one for a POLITY interregnum period, indicating a period of political turmoil.

The second set of measures comes from the Archigos dataset on political leaders (Goemans et al 2006). This dataset classifies the primary national political leader for each country and year and codes all leader transitions into two categories: "regular" transitions, which take place according to the prevailing institutional rules of the country, and "irregular" transitions (such as coups), which do not follow the prevailing institutional rules. We consider a dummy variable for years with leadership transitions, as well as separate dummy variables for regular and irregular transitions.

The results are presented in Table 6. Looking first at POLITY, an additional $1^{\circ} \mathrm{C}$ in poor countries is associated with a (statistically insignificant) 2.3 percentage point increase in the probability of any change in POLITY. Column (2) shows that a $1^{\circ} \mathrm{C}$ increase in temperature leads to a 2.3 percentage point increase in the probability of a POLITY interregnum period,

\footnotetext{
${ }^{22}$ Medical studies have documented that levels of platelet paroxitine - a chemical that blocks impulsivity and aggression - fall when temperatures increase and have linked low levels of platelet paroxitine to higher rates of aggression (Tihonen et al., 1997). Violent crime also increases with temperature (Jacob et al. 2007).
} 
which suggests that all of the changes in POLITY induced by temperature occur through increases in political instability. Though these effects are statistically insignificant (p-values of 0.16 and 0.20 respectively), the estimated magnitudes are substantial, given that the baseline probability of a POLITY change in poor countries is 13.1 percent and the baseline probability of an interregnum period in poor countries is only 5.7 percent. The results on precipitation are somewhat weaker, but suggest that political change in poor countries is more likely in years with lower rainfall.

The Archigos results show a similar pattern and are stronger statistically. A one degree rise of temperature raises the probability of leader transitions by 3.7 percentage points in poor countries (column 3). Moreover, this effect comes not from regular leadership transitions (column 4) but from irregular leader transitions - i.e. coups (column 5). This effect of 3.9 percentage points is large, as the baseline probability of an irregular leader transition is only 4.5 percent per year in poor countries. By contrast, we see no effects on leader transitions in rich countries.

Combined, the POLITY and Archigos data tell a consistent story: higher temperatures are associated with political instability in poor countries. Whether temperature has direct effects on political instability, which in turn affects economic growth, or whether temperature has direct effects on economic growth, which in turn affects political instability - or both - is difficult to distinguish, since poor economic performance and political instability are likely mutually reinforcing. Nevertheless, the impact of temperature on political instability in poor countries is suggestive of an institutional mechanism through which temperature might affect productivity growth, rather than just the level of income. 
The final columns of Table 6 consider the impact of temperature and precipitation on conflict. We use the PRIO conflict data (PRIO 2006), which indicates for every country-year whether the country was involved in a high-intensity conflict (defined as $\geq 1,000$ conflict deaths / year) or a low-intensity conflict (defined as 25 to 1000 conflict deaths / year). Column (6) examines the start of conflicts (i.e., the probability a conflict begins given no conflict in the previous period), and column (7) examines the end of conflicts (i.e., the probability a conflict ends given conflict in the previous period). ${ }^{23}$ We find no significant effect of temperature or precipitation on either the start or conclusion of conflicts. ${ }^{24}$ The political impacts of temperature and precipitation thus appear more concentrated in political instability rather than outright civil or interstate wars.

\section{The longer-run}

In this section, we re-examine the historical data to investigate longer-term climate changes. We then discuss some illustrative implications of climate change obtained by integrating our historical estimates with standard climate projections.

\subsection{Longer-run historical estimates}

The short-run panel estimates indicate substantial effects of temperature shocks in poor countries, with per-capita income growth falling approximately 1 percentage point for a $1^{\circ} \mathrm{C}$ rise in temperature. Although this effect persists for 10 years in the panel model, the effect of sustained temperature increases might attenuate over time if economies adapt. On the other hand,

\footnotetext{
${ }^{23}$ Given how rare conflicts are, we use year fixed effects rather than region-by-year fixed effects in these specifications.

${ }^{24}$ These results differ from Miguel et al. (2004), who find - also using the PRIO dataset - that greater precipitation is associated with a lower probability of conflict. Miguel et al. examine only Sub-Saharan African countries from 1981-1999, and use a somewhat different empirical specification from the one in Table 6.
} 
sustained higher temperatures may reinforce growth-related problems by placing continued pressure on political systems, health, crime, or other channels.

We therefore consider the longer-run analogue of our panel specification, examining the relationship between climatic changes and growth changes in the early and late periods in our dataset. There is substantial heterogeneity in temperature increases over this period, with countries such as Tunisia, Zambia, and Botswana warming by approximately $1{ }^{\circ} \mathrm{C}$ since the mid 1980s, while others such as Laos, Kenya, and Nigeria experienced almost no warming over the same period. We exploit this variation to ask whether countries with sustained warming saw sustained changes in growth.

Specifically, we estimate the following regression

$$
\bar{g}_{i 2}-\bar{g}_{i 1}=\alpha+\theta_{r}+\gamma\left(\bar{T}_{i 2}-\bar{T}_{i 1}\right)+\varepsilon_{i}
$$

where $\bar{g}_{i 1}$ is the mean growth rate in country $i$ in the early period (1970-1985 in our main specification) and $\bar{g}_{i 2}$ is the mean growth rate in the late period (1986-2000). ${ }^{25}$ Mean temperature and precipitation in these periods are $\bar{T}_{i 1}$ and $\bar{T}_{i 2}$, while $\theta_{r}$ captures region fixed effects and a dummy for being poor, and $\varepsilon_{i}$ is an independently distributed error term. This firstdifferenced regression is the longer-run version of the fixed effects panel model in equation (4). To see this, start with equation (4) with no lags, take averages of the left- and right-hand sides for a given period, and then first-difference. We have one observation per country, having

\footnotetext{
${ }^{25}$ We begin in the $1970 \mathrm{~s}$, rather than an earlier decade such as the $1960 \mathrm{~s}$, because we lose most of the poor countries in our sample when we extend the sample back to the 1960s. We present results for a variety of alternative time periods below.
} 
differenced out any initial conditions or other fixed national characteristics that might influence growth. $^{26}$

Table 7 presents the results. The baseline specification compares the 1970-1985 period to the 1986-2000 period and shows substantial, statistically significant negative effects of warming on poor countries. In column (1), a temperature rise of $1^{\circ} \mathrm{C}$ reduces annual growth in poor countries by 3.2 percentage points. The inclusion of region fixed effects does not substantially change this effect, as shown in column (2). When we split the sample into Sub-Saharan African countries (column 7) and all other countries (column 8), we find similar effects in both samples, though the estimates are not statistically significant. ${ }^{27}$ Using WDI data instead of PWT data finds $1^{\circ} \mathrm{C}$ reduces annual growth in poor countries by 2.3 percentage points (column 9 ). ${ }^{28}$

The statistical significance of the results is more sensitive to the estimation period used, although the point estimates remain large and negative in all specifications. When using the time series up to the final year of the data, comparing slightly longer periods from 1970-1987 and 1988-2003, we find very similar results (column 3). When comparing shorter periods over various intervals, such as the 1990s to the 1960s (column 4), the 1990s to the 1970s (column 5), and the 1990s to the 1980s (column 6), we find similar point estimates of the effect of temperature on poor countries, but less statistical significance.

Overall, this analysis continues to suggest substantial negative effects of warming on growth in poor countries. Moreover, the estimated effect in the longer-run analysis is typically

\footnotetext{
${ }^{26}$ Note also that, in cross-section, average growth is substantially lower in warmer countries over this period. While interesting, this is less well identified than the first differenced results, which net out unobserved fixed country characteristics.

${ }^{27}$ The Africa sample shows similarly large effects in poor countries as other specifications, but the standard errors have increased with the substantially smaller sample size, so the result is not quite statistically significant.

${ }^{28}$ With so few observations, one might be concerned that a few outliers drive the results. However, we find very similar results using median regressions, which give much less weight to outliers. For example, using median regressions, the estimated impact on poor countries in column (1) is $-2.30(\mathrm{p}=0.075)$, as opposed to a coefficient of $-2.34(\mathrm{p}=0.020)$ using OLS (results available on request).
} 
larger than in the short-run panel analysis. Thus, just as the 5 and 10 year lag results (Tables 3 and 4) suggest that the growth effect strengthens the longer the time interval considered, the longer-run relationship in Table 7 tends to show even larger point estimates. Put another way, we find little evidence that poor countries adapt and eliminate the negative consequences of warming over the time horizons considered here.

\subsection{Illustrative Projections}

This section considers potential economic implications of future climate change. Given the wide range of assumptions required to make projections, any projections should be viewed with considerable skepticism. Our purpose is simply to illustrate some of the longer-run issues that the historical estimates might imply.

Our analysis integrates the estimated marginal effects of climate change with standard climate projections over the $21^{\text {st }}$ century. The projection calculations follow two steps. First, we use a standard climate model to determine projected temperature increases for each country and year through $2099 .{ }^{29}$ Second, we calculate marginal growth effects of these temperature increases for each country and year. ${ }^{30}$ Note that the marginal growth effect depends on whether the country is rich or poor at the time, which depends partly on the country's background growth rate. We project the background growth rate using the country's historical growth rate, allowing for country-specific convergence rates to U.S. income levels. This methodology is detailed in Appendix III.

A key issue in making projections concerns the speed of adaptation to climate change. Since our estimates suggest that the growth effects of climatic change persist over at least a 10-

\footnotetext{
${ }^{29}$ Climate projections depend on the greenhouse gas emissions scenario and the climate model. We use climate predictions from a standard model, the Community Climate System Model (CCSM) v3.0 (UCAR 2007), and present results from the A2 (high) emission scenario. More details can be found in IPCC (2007).

${ }^{30}$ These growth effects are taken from the 10-year panel model in column (1) of Table 4 . The general patterns are similar when employing alternative historical estimates.
} 
year period, we take 10 years as a lower-bound adaptation horizon. We also consider adaptation horizons of 25 and 50 years, and, for comparison purposes, present a benchmark scenario in which adaptation never occurs. In the adaptation scenarios, we calculate temperature impacts by assuming countries adjust completely to their climate $\mathrm{N}$ years in the past, so that the marginal effect on growth is calculated using the difference between the temperature in a given year and the temperature $\mathrm{N}$ years before. ${ }^{31}$

Table 8 illustrates the effects of climate change under these different adaptation horizons. The results show that the cumulative growth effect in poor countries could be quite large. With a 10-year adaptation horizon, so that countries adapt quickly to climatic changes, the median growth rate among poor countries appears 0.6 percentage points lower through 2099 compared to the case of no warming. With a 50-year adaptation horizon, the median growth rate appears 2.3 percentage points lower than the no warming case. Moreover, because the growth effects are large for poor countries - and because we estimate no impact on rich countries - the estimates in Table 8 suggest that climate change could substantially widen world income inequality.

To gauge what these growth rates imply, consider the Pritchett (1997) idea of a subsistence-level consumption floor. Suppose that floor is the $1^{\text {st }}$ percentile of per-capita income in the Penn World Tables, which is $\$ 425$ per capita in year 2000 purchasing-power-parity dollars. In that case, 13 countries (11\% of the sample) are projected to hit this floor in 2099 with a 10-year adaptation horizon, and $37(30 \%)$ are projected to hit this floor with a 50-year adaptation horizon, compared to only 9 countries with no climate change. ${ }^{32}$ Thus, depending on

\footnotetext{
${ }^{31}$ One may also imagine models where individuals adapt not to the level of temperature but to its rate of change. This possibility is not pursued here.

${ }^{32}$ Note that the calculations in Table 8 do not account for this lower bound. If we assume countries cannot go below this lower bound, the results are virtually identical, except that the rise in world 75/25 inequality in the no-adaptation scenario is capped at $700 \%$ instead of $2100 \%$.
} 
the speed of adaptation, climate change could potentially move many countries towards the historical consumption lower bound. ${ }^{33}$

Despite these large, negative effects for poor countries, we find very little impact of climate change on world GDP. This result follows from (a) the absence of estimated temperature effects in rich countries and (b) the fact that rich countries make up the bulk of world GDP. Moreover, if rich countries continue to grow at historical rates, their share of world GDP becomes more pronounced by 2099, so even a total collapse of output in poor countries has a relatively small impact on total world output. ${ }^{34}$

\subsection{Discussion}

Our estimated effects differ from those predicted by traditional, IAM-based approaches, which show neither the large effects we find in poor countries nor the large dichotomy between rich and poor countries. These differences come primarily for three reasons. First, we rely on aggregate data to estimate the effects, rather than assuming a set of channels and adding them up as in IAM approaches. Estimating aggregate effects directly helps capture important channels, and interactions between channels, which are not captured by the disaggregated approach. Second, IAM approaches often build the underlying sector-specific models from evidence of behavior in rich countries. As demonstrated in this paper, the effects of climate change in rich and poor countries are different, so extrapolating analyses of rich-countries is likely to understate the effects in poorer regions. Finally, most existing literature assumes that temperature will affect the level of output, as opposed to the growth rate of output. In our method, we consider the

\footnotetext{
${ }^{33}$ As economies tend toward the lower bound for subsistence, historical evidence suggests that fertility, mortality, and/or migration would respond to restore equilibrium (Lavely and Wong, 1998, Wrigley and Schofield, 1981).

${ }^{34}$ Note that the rapid growth of India and China suggest that they will quickly cross the 'rich country' threshold, and therefore in the projections they are not assigned significant negative consequences of climate change.
} 
possibility of both level and growth effects. Because growth effects compound over time, even modest growth effects can accumulate into large income effects.

While the estimated impacts of climate change may seem large, it is worth recalling the strong cross-sectional correlation between per-capita income and temperature across the world. A simple cross-section regression in the year 2000 shows that a $1^{\circ} \mathrm{C}$ increase in average temperature predicts a fall in per-capita income by $0.085 \log$ points (i.e. about 8 percent). Viewed in this light, the estimated magnitudes in this paper seem less surprising. For example, with a 10 -year adaptation horizon and a 1.1 percentage point loss in growth for each $1^{\circ} \mathrm{C}$ warming (i.e., the estimated effect in Table 2), a permanent increase in temperature of $1^{\circ} \mathrm{C}$ would reduce income permanently by $0.11 \log$ points $(-0.011 * 10)$ - which is close to what the world cross-section also predicts. While the magnitudes we estimate are large, when allowing for reasonably rapid adaptation they suggest effects on the same order of magnitude as the overall temperature-output relationship we observe in the world today.

\section{Conclusion}

This paper presents new estimates for the effect of climatic changes on national economies. Our approach differs from standard "Integrated Assessment Models", where authors postulate a set of climate-economy mechanisms and sum them up. In this paper, we estimate climate effects directly by examining the historical relationship between climate fluctuations and economic growth.

We find substantial effects of climatic changes, but only in poor countries. In poor countries, a $1{ }^{\circ} \mathrm{C}$ rise in temperature in a given year reduces economic growth by 1.1 percentage points on average. The estimates suggest that climate change may affect the rate of economic 
growth, rather than just the level of output. Moreover, estimates using the overall change in climate from 1970 to 2000 rather than annual variation produce even larger estimates, suggesting that adaptation may not undo these effects in the medium term.

While higher temperatures reduce agricultural output in poor countries, we also find that they lead to contractions in industrial output and aggregate investment and to increased political instability. These results underscore the breadth of mechanisms underlying the climate-economy relationship. The results also suggest that future climate change may substantially widen income gaps between rich and poor countries, with many poor countries driven toward greater poverty, other things equal. Further work is needed to identify precise causal mechanisms. This paper suggests such analysis is of first-order importance, as the economic effects in poor countries appear large. 


\section{Appendix I: Climate Data}

Our primary source for climate data is the Terrestrial Air Temperature and Precipitation: 19002006 Gridded Monthly Time Series, Version 1.01 (2007), compiled by Kenji Matsuura and Cort Willmott in conjunction with NASA. The data are available at http://climate.geog.udel.edu/ $\sim$ climate/html_pages/download.html. This dataset combines station data on mean air temperature and precipitation from a number of sources, with the primary source being the Global Historical Climatology Network (Peterson and Vose, 1997).

Matsuura and Willmott interpolate monthly averages of air temperature and precipitation to a 0.5 degree by 0.5 degree latitude/longitude grid. The gridded fields were estimated from monthly weather-station averages using a combination of spatial interpolation methods: digital-elevationmodel (DEM) assisted interpolation (temperature only; Willmott and Matsuura, 1995); traditional interpolation (Willmott et al., 1985); and climatologically aided interpolation (CAI) (Willmott and Robeson, 1995). An average of twenty nearby stations influenced each grid-node estimate.

We calculate the average yearly temperature and precipitation within each country using geospatial software. We investigate several weighting schemes: landmass area, population, urban population, and rural population. Landmass weights weight each temperature or precipitation cell by the fraction of the country's landmass it covers. Urban (rural) population weights limit the sample to urban (rural) areas. Population and urban extents data for 1990 are at a resolution of 30 arc seconds (approximately one kilometer at the equator) and were produced by Columbia University’s Center for International Earth Science Information Network (SEDAC, 2004).

\section{Appendix II: Dynamic Regression Models}

This section discusses and estimates a more general econometric model for identifying growth effects in the context of a dynamic panel growth regression, following the derivation in Bond et al. (2007). To begin, consider a general dynamic growth equation for the log-level of per-capita output:

$$
y_{i t}=A_{i t}+\alpha_{1} y_{i t-1}+\ldots+\alpha_{p} y_{i t-p}+\beta_{0} T_{i t}+\beta_{1} T_{i t-1}+\ldots+\beta_{p} T_{i t-p}+\varepsilon_{i t}
$$

This equation generalizes equation (1) in the text by adding $p$ lags of temperature, allowing output to depend on $p$ lags of past output, and adding an error term.

We assume that $A_{i t}$ evolves according to a generalized version of the dynamic process specified in (2) with $p$ lags, i.e.

$$
\Delta A_{i t}=g_{i}+\gamma_{0} T_{i t}+\ldots+\gamma_{p} T_{i t-p}
$$

This form allows both current and lagged temperature to affect the growth rate of $A$.

Substituting (A1.2) into the first differenced version of (A1.1) yields a dynamic panel estimation equation of the form:

$$
\begin{aligned}
\Delta y_{i t} & =g_{i}+\alpha_{1} \Delta y_{i t-1}+\ldots+\alpha_{p} \Delta y_{i t-p} \\
& +\gamma_{0} T_{i t}+\ldots+\gamma_{p} T_{i t-p}+\beta_{0} \Delta T_{i t}+\beta_{1} \Delta T_{i t-1}+\ldots+\beta_{p} \Delta T_{i t-p}+\Delta \varepsilon_{i t}
\end{aligned}
$$

Rewriting the $\Delta T$ terms as $T$ terms yields 


$$
\begin{aligned}
\Delta y_{i t}= & g_{i}+\alpha_{1} \Delta y_{i t-1}+\ldots+\alpha_{p} \Delta y_{i t-p}+ \\
& \left(\gamma_{o}+\beta_{0}\right) T_{i t}+\left(\gamma_{1}+\beta_{1}-\beta_{0}\right) T_{i t-1}+\ldots+\left(\gamma_{p}+\beta_{p}-\beta_{p-1}\right) T_{i t-p}-\beta_{p} T_{t-p-1}+\Delta \varepsilon_{i t}
\end{aligned}
$$

or, relabeling the coefficients on $T$,

$$
\Delta y_{i t}=g_{i}+\alpha_{1} \Delta y_{i t-1}+\ldots+\alpha_{p} \Delta y_{i t-p}+\sum_{j=0}^{p+1} \rho_{j} T_{i j}+\Delta \varepsilon_{i t}
$$

To find the growth effect, consider what happens if temperature is constant and growth is in steady-state, i.e., $\Delta y_{i t-j}=\Delta y$ and $T_{i j}=T$. Solving equation (A1.5) shows that

$$
\Delta y_{i}=\frac{g_{i}}{1-\alpha_{1}-\ldots-\alpha_{p}}+\frac{\sum_{j=0}^{p+1} \rho_{j}}{1-\alpha_{1}-\ldots-\alpha_{p}} T_{i}
$$

so that the growth effect of temperature is simply $\frac{\sum_{j=0}^{p+1} \rho_{j}}{1-\alpha_{1}-\ldots-\alpha_{p}}$. From (A1.4), it is also clear that this is identical to $\frac{\sum_{j=0}^{p} \gamma_{j}}{1-\alpha_{1}-\ldots-\alpha_{p}}$, since the $\beta$ terms all cancel.

As noted by Bond et al. (2007), estimation of (A1.5) is complicated by the fact that the error term, $\Delta \varepsilon_{i t}$, is correlated with the lagged dependent variable, $\Delta y_{i t-1}$. Bond at al. suggest instrumenting for $\Delta y_{i t-1}$ with further lags of growth. However, since growth is only very weakly serially correlated (the correlation of growth and lagged growth is only 0.07 ), these instruments are very weak.

Given these issues, as well as the very low serial correlation in growth, we focus in the text on (4), which imposes $\alpha_{j}=0$ for all $j$. However, for completeness, Appendix Table 1 presents estimates of the growth effect for poor countries under a variety of alternative empirical specifications that estimate $\alpha$ flexibly. For convenience, the first row of Appendix Table 1 replicates the equivalent results from Table 3, which imposes $\alpha_{j}=0$ for all $j$. The second row of Appendix Table 1 report estimates of (A1.5) with 1 lag of growth. The reported coefficients are the implied growth effects for poor countries from equation (A1.6). The third and fourth rows of Appendix Table 1 estimate (A1.5) with $p$ lags of growth, where $p=1$ in column (1), $p=4$ in column (2) and $p=9$ in column (3), which means that a total of 1, 5 and 10 lags of temperature, respectively, are included in the regression. The third row presents OLS results and the fourth row presents results instrumenting for the first lag of growth with the $p+1$ lag.

Broadly speaking, these results are very similar to the main results shown in the paper. If anything, the estimated growth effects from the dynamic panel specifications tend to be slightly larger in magnitude than the results that do not include lags of growth. As expected given the low serial correlation of growth, the IV results are less precisely estimated than the OLS results, although the 10 lag IV results remain statistically significant.

Finally, as an additional check on the empirical specification, we have run Monte Carlo analyses of (4) using actual output and climate data to ensure that this econometric specification provides correct inference and unbiased estimates. Specifically, in each Monte Carlo iteration, we randomly reassigned the temperature series from one to country to another country's real output series, and then tested for temperature effects in model (4). 
With random reassignment, we rejected the null of no climate effects at the $5 \%$ significance level approximately $4 \%$ of the time, suggesting that our inference is accurate against the null hypothesis of no climate effects and, if anything, is slightly conservative. In additional simulations, we again randomly reassigned the real climate series of one country to the real output series of another country, but then adjusted each output series according to assumed growth and level effects of temperature. These Monte Carlos showed that the distributed lag coefficients, and the cumulated lags, provided unbiased estimates for both level effects and growth effects of temperature. These Monte Carlo results are available from the authors upon request.

\section{Appendix III: Projections Methodology}

1. Future temperature

The CCSM v3.0 model provides gridded, monthly air temperature projections with a spatial resolution of $1.4 \times 1.4$ degrees. Annual country averages are calculated by taking arithmetic, population-weighted means for each country. This aggregation method is the same as that used for the historical climate data as described in the text. The CCSM projection data are provided by the University Corporation for Atmospheric Research (UCAR) and can be downloaded at http://www.gisclimatechange.org.

\section{Future growth}

The marginal growth effect in any country in any future year is calculated in two parts. First, we calculate the marginal increase in temperature in that country and year versus in the baseline of no warming. Second, we calculate the marginal effect of the temperature change on economic growth, which depends on whether the country is rich or poor in the given year. The marginal growth effect of temperature for rich and poor countries is taken from the 10-lag model presented in Column 1 of Table 4. In the historical data, the absolute level of income per-capita that separates rich and poor countries is $\$ 3170$ (PPP, year 2000 dollars). Regression models based on finer gradations of income $(3,4$, or 5 quantiles instead of 2$)$ produce broadly similar results.

Whether a country is rich or poor in the future depends in part on the accumulation of marginal growth effects from climate and in part on the background growth rate for the country. To calculate the baseline growth rate, we assume that countries grow in the future at their historical rate over the 1971-2003 period (or the 1991-2003 period if the longer period is not available). This growth rate is further adjusted for "conditional convergence", by correcting for country-specific convergence rates to United States income levels. This ensures, for example, that countries like China do not continue at high growth forever but ultimately slow as they come closer to United States per-capita income. The convergence term, $\beta_{i}$, for country $i$ is calculated such that

$$
\bar{g}_{i}=\bar{g}_{U S}+\beta_{i}\left(\ln y_{U S, 1971}-\ln y_{i, 1971}\right)
$$

where $\bar{g}_{i}$ is the average growth rate in country i from 1971-2003, $\bar{g}_{U S}$ is the equivalent average for the United States, and $\ln y_{U S, 1971}$ and $\ln y_{i, 1971}$ are log per-capita income in the US and country 
$\mathrm{i}$, respectively, in $1971 .^{35}$ The baseline growth rate for any year $t$ in the future is then calculated as

$$
g_{i, t}^{B}=\bar{g}_{U S}+\beta_{i}\left(\ln y_{U S, t}-\ln y_{i, t}\right)
$$

The estimated growth rate in year $t$ is this baseline growth rate plus the marginal effect of temperature in that year

$$
g_{i, t}=g_{i, t}^{B}+\gamma^{P} \Delta T_{i, t} I_{i, t}+\gamma^{R} \Delta T_{i, t}\left(1-I_{i, t}\right)
$$

where $\Delta T_{i, t}$ is the change in temperature against the baseline of no warming, $I_{i, t}$ is an indicator equal to 1 if the country is poor, and $\gamma^{P}$ and $\gamma^{R}$ are the growth effects for poor and rich countries, respectively, as calculated from the panel model. In the projections presented in Table 8 , we set $\gamma^{R}=0$. Starting in the present, we use these calculated growth rates to project percapita income forward year-by-year for each country. The results in Section 5 present economic projections under the A2 scenario compared against the case of no climate change (where $\Delta T_{i, t}=0$ for all $i$ and $\left.t\right)$.

\footnotetext{
${ }^{35}$ For countries with growth data that begins after 1971 we use 1991 instead. If a country's convergence term appears negative (i.e. it grows more slowly than the U.S. historically), then we set the convergence rate to zero and simply set the baseline growth rate to the country's historical average.
} 


\section{References}

Adams, Richard M. et al. "Global Climate Change and US Agriculture," Nature 345, 219-224, 1990.

Balk, Deborah et al. Center for International Earth Science Information Network (CIESIN), Columbia University; International Food Policy Research Institute (IFPRI), the World Bank; and Centro Internacional de Agricultura Tropical (CIAT), 2004. Global Rural-Urban Mapping Project (GRUMP), Palisades, NY: CIESIN, Columbia University. Available at http://sedac.ciesin.columbia.edu/gpw, 2004.

Bond, Stephen R., Asli Leblebicioglu, and Fabio Schiantarelli, "Capital Accumulation and Growth: A New Look at the Empirical Evidence," mimeo, University of Oxford, 2007.

Boyanowsky, Ehor. "Violence and Aggression in the Heat of Passion and in Cold Blood: The Ecs-TC Syndrome," International Journal of Law and Psychiatry 22(3): 257-271, 1999.

Brohan, Phillip, John Kennedy, I. Haris, Simon Tett and Pete Jones. "Uncertainty estimates in regional and global observed temperature changes: A new data set from 1850," Journal of Geophysical Research 111, 2006.

Carlsmith, J. Merrill and Craig A. Anderson, "Ambient Temperature and the Occurrence of Collective Violence: A New Analysis," Journal of Personality and Social Psychology 37 (3), 337-344, 1979.

Curriero, Frank C., Karlyn Heiner, Jonathan Samet, Scott Zeger, Lisa Strug, Jonathan A.Patz. "Temperature and Mortality in 11 Cities of the Eastern United States," American Journal of Epidemiology 155(1):80-87, 2002.

Deschenes, Olivier and Michael Greenstone, "The Economic Impacts of Climate Change: Evidence from Agricultural Output and Random Fluctuations in Weather," American Economic Review 97, 354-385, 2007.

Deschenes, Olivier and Enrico Moretti, "Extreme Weather Events, Mortality, and Migration", NBER Working Paper \#13227, 2007.

Field, Simon. "The Effect of Temperature on Crime," The British Journal of Criminology 32:340-351, 1992.

Goemans, Hein, Kristian Gleditsch and Giacomo Chiozza. "Archigos: A Database of Leaders 1875-2004”, http://mail.rochester.edu/ hgoemans/data, 2006.

Guiteras, Raymond. "The Impact of Climate Change on Indian Agriculture," mimeo, MIT Department of Economics, 2007.

Heston, Alan, Robert Summers and Bettina Aten, Penn World Table Version 6.2, Center for International Comparisons of Production, Income and Prices at the University of Pennsylvania, September 2006.

Hornbeck, Richard, "Long-term Adjustment to Environmental Change: Evidence from the American Dust Bowl," mimeo, MIT Department of Economics, 2007.

Huntington, Ellsworth. Civilization and Climate, New Haven, CT: Yale University Press, 1915.

Intergovernmental Panel on Climate Change. IPCC Fourth Assessment Report, Working Groups I, II, and III (http://www.ipcc.ch/), 2007.

Jacob, Brian, Lars Lefgren and Enrico Moretti. "The Dynamics of Criminal Behavior: Evidence from Weather Shocks" Journal of Human Resources, 2007. 
Lavely, William and R. Bin Wong. "Revising the Malthusian Narrative: The Comparative Study of Population Dynamics in Late Imperial China," The Journal of Asian Studies 57(3), 716$718,1998$.

Link James and Robert Pepler. 1970. "Associated fluctuations in daily temperature, productivity and absenteeism.” No 2167 RP-57, ASHRAE Transactions, vol 76, Part II, 326-337, 1970.

Marshall, Alfred. Principles of Economics. London: Macmillan and Co. 1920 [1890].

Marshall, Monty G., and Keith Jaggers. Polity IV Project, Integrated Network for Societal Conflict Research Program and Center for International Development and Conflict Management, University of Maryland, 2004.

Matsuura, Kenji and Cort Willmott. Terrestrial Air Temperature and Precipitation: 1900-2006 Gridded Monthly Time Series, Version 1.01, University of Delaware, http://climate.geog.udel.edu/ climate/, 2007.

Meehl, Gerald, Claudia Tebaldi, and Doug Nychka. "Changes in frost days in simulations of 21st century climate." Climate Dynamics, Vol. 23, No. 5, 495-511, 2004.

Meese, G., R. Kok, M. Lewis, and D. Wyon. "Effects of Moderate Cold and Heat Stress on Factory Workers in Southern Africa” South Africa Journal of Science 78: 189-197, 1982.

Mendelsohn, Robert, Wendy Morrison, Michael Schlesinger and Natalia Andronova. "Countryspecific market impacts of climate change," Climatic Change 45(3-4): 553-569, 2000.

Mendelsohn, Robert, Ariel Dinar, and Apurva Sanghi. "The Effect of Development on the Climate Sensitivity of Agriculture," Environmental and Development Economics 6, 85-101, 2001.

Miguel, Edward, Shanker Satyanath and Ernest Sergenti. "Economic Shocks and Civil Conflict: An Instrumental Variables Approach," Journal of Political Economy 112(4), 725-753, 2004.

Montesquieu, Charles de. The Spirit of Laws, 1750.

Neng, Shi, Chen Luwen, and Xia Dongdong. "A Preliminary Study on the Global Land Annual Precipitation Associated with ENSO during 1948-2000," Advances in Atmospheric Sciences 19: 993-1003, 2002.

New, Mark, Martin Todd, Mike Hulme, and Phil Jones. "Precipitation measurements and trends in the twentieth century." International Journal of Climatology 21, 1899-1922, 2001.

Nicholls, Robert and Stephen Leatherman (eds.) "Potential Impacts of Accelerated Sea-Level

Rise on Developing Countries," Journal of Coastal Research, Special Issue No. 14, 1995.

Nordhaus, William. "Geography and Macroeconomics: New Data and Findings," Proceedings of the National Academy of Science 103, 3510-3517, 2006.

Nordhaus, William and Joseph Boyer, Warming the World: The Economics of the Greenhouse Effect, Cambridge, MA: MIT Press, 2000.

Pritchett, Lant. "Divergence, Big Time," Journal of Economic Perspectives 11, 3-17, 1997.

PRIO, Armed Conflict Data Version 4. Available at http://new.prio.no/CSCW-Datasets/Data-onArmed-Conflict/UppsalaPRIO-Armed-Conflicts-Dataset/, 2006.

Stern, Nicholas, The Economics of Climate Change: The Stern Review, Cambridge, England: Cambridge University Press, 2007.

Tol, Richard. "Estimates of the damage costs of climate change - part II: dynamic estimates," Environmental and Resource Economics 21, 135-160, 2002. 
U.S. Riot Commission. Report of the National Advisory Commission on Civil Disorders. New York: Bantam Books, 1968.

University Corporation for Atmospheric Research (UCAR). GIS Climate Change Scenarios, http://www.gisclimatechnage.org, September 2007.

World Bank, 2007 World Development Indicators Online Edition, 2007.

Wrigley, Edward Anthony and Robert Schofield. The Population History of Britain 1541-1871: A Reconstruction. London, England: Edward Arnold, 1981.

Wyon, David. "Assessing the effects of moderate heat and cold stress on human efficiency," Paper no. 6 of Proceedings of the Symposium, Factories for Profit - Environmental Design, National Building Research Institute, Pretoria, September 14-16 1976. 
Raw data

After removing worldwide year fixed effects

After removing region $\times$ year and poor $\times$ year fixed effects

Raw data

After removing worldwide year fixed effects

After removing region $\times$ year and poor $\times$ year fixed effects

\begin{tabular}{lccccr}
\multicolumn{4}{l}{ Proportion of country-years with temperature $[\ldots]$ degrees above/below country mean: } \\
0.25 & 0.50 & 0.75 & 1.00 & 1.25 & 1.50 \\
0.570 & 0.294 & 0.144 & 0.065 & 0.029 & 0.011 \\
0.508 & 0.213 & 0.085 & 0.034 & 0.013 & 0.005 \\
& & & & & 0.008 \\
0.451 & 0.158 & 0.054 & 0.020 & 0.003
\end{tabular}

Proportion of country-years with precipitation [...] $100 \mathrm{~mm}$ units above/below country mean:

$\begin{array}{cccccc}1 & 2 & 3 & 4 & 5 & 6 \\ 0.480 & 0.229 & 0.123 & 0.072 & 0.044 & 0.029 \\ 0.495 & 0.222 & 0.113 & 0.063 & 0.039 & 0.025 \\ 0.461 & 0.213 & 0.106 & 0.060 & 0.034 & 0.022\end{array}$


Table 2: Main panel results

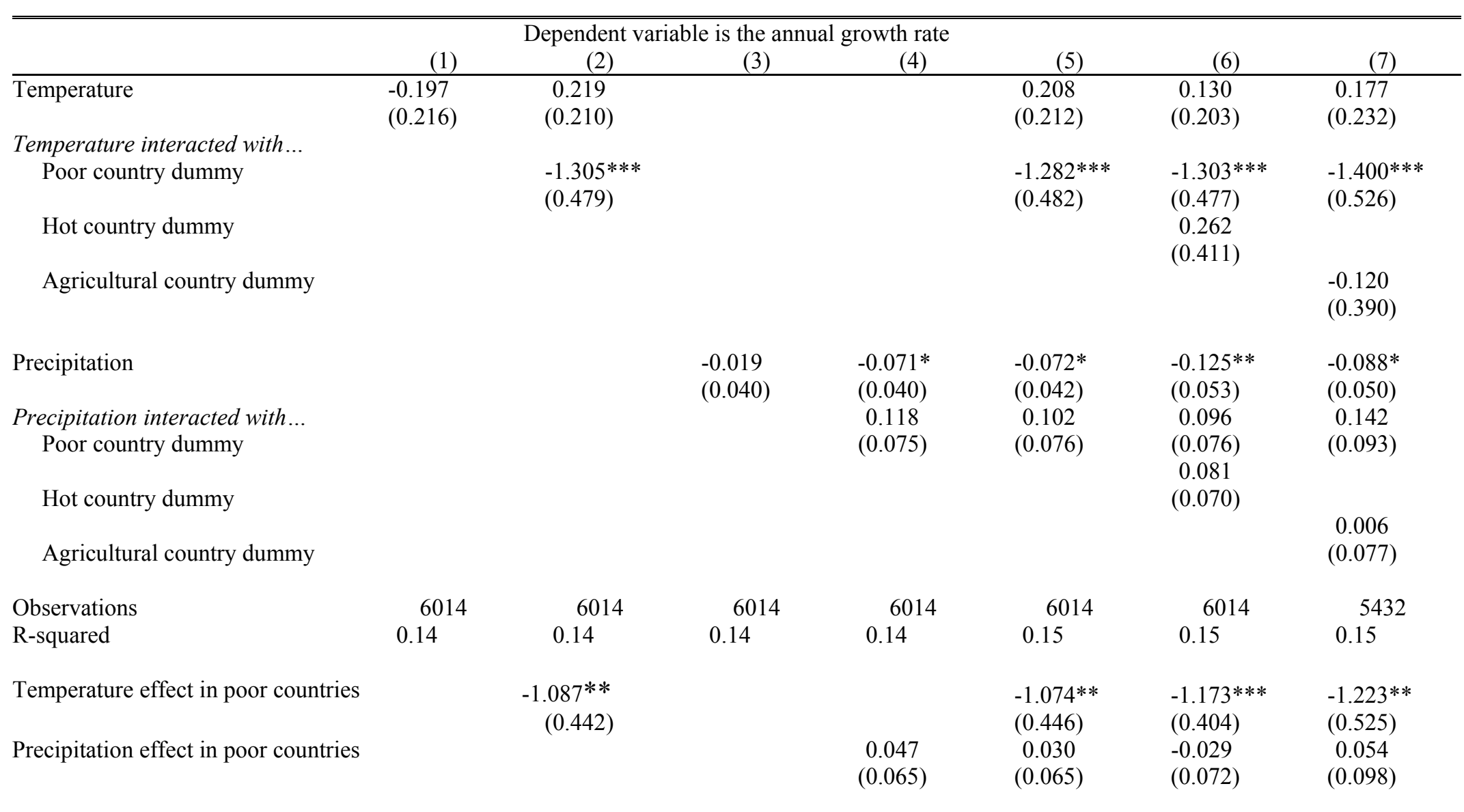

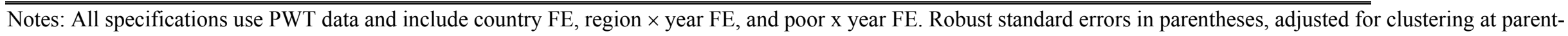

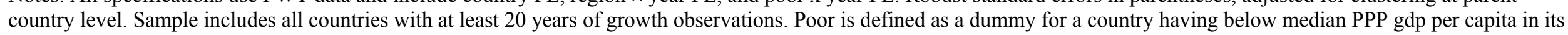

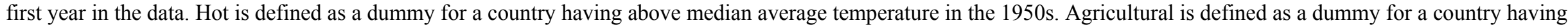
above median share of GDP in agriculture in 1995. Temperature is in degrees Celsius and precipitation is in units of $100 \mathrm{~mm}$ per year.

$*$ significant at $10 \% ; * *$ significant at $5 \% ; * * *$ significant at $1 \%$ 
Table 3: Models with lags

\begin{tabular}{|c|c|c|c|c|c|c|c|c|c|c|}
\hline & $\begin{array}{c}(1) \\
\text { No lags }\end{array}$ & $\begin{array}{l}(2) \\
1 \mathrm{lag}\end{array}$ & $\begin{array}{c}(3) \\
3 \text { lags }\end{array}$ & $\begin{array}{c}(4) \\
5 \text { lags }\end{array}$ & $\begin{array}{c}(5) \\
10 \text { lags }\end{array}$ & $\begin{array}{c}(6) \\
\text { No lags }\end{array}$ & $\begin{array}{l}(7) \\
1 \mathrm{lag}\end{array}$ & $\begin{array}{c}(8) \\
3 \text { lags }\end{array}$ & $\begin{array}{c}(9) \\
5 \text { lags }\end{array}$ & $\begin{array}{c}(10) \\
10 \text { lags }\end{array}$ \\
\hline Temperature $\times$ Poor & $\begin{array}{l}-1.087 * * \\
(0.442)\end{array}$ & $\begin{array}{l}-0.954 * \\
(0.559)\end{array}$ & $\begin{array}{l}-0.932 * \\
(0.560)\end{array}$ & $\begin{array}{l}-0.933 * \\
(0.562)\end{array}$ & $\begin{array}{l}-1.112 * \\
(0.586)\end{array}$ & $\begin{array}{l}-1.074 * * \\
(0.446)\end{array}$ & $\begin{array}{l}-0.945^{*} \\
(0.558)\end{array}$ & $\begin{array}{l}-0.925 * \\
(0.557)\end{array}$ & $\begin{array}{l}-0.925 \\
(0.559)\end{array}$ & $\begin{array}{l}-1.071 * \\
(0.585)\end{array}$ \\
\hline L2: Temperature $\times$ Poor & & & $\begin{array}{l}-0.210 \\
(0.441)\end{array}$ & $\begin{array}{l}-0.183 \\
(0.459)\end{array}$ & $\begin{array}{l}-0.120 \\
(0.485)\end{array}$ & & & $\begin{array}{l}-0.249 \\
(0.443)\end{array}$ & $\begin{array}{l}-0.226 \\
(0.458)\end{array}$ & $\begin{array}{l}-0.140 \\
(0.484)\end{array}$ \\
\hline L3: Temperature $\times$ Poor & & & $\begin{array}{l}-0.216 \\
(0.519)\end{array}$ & $\begin{array}{l}-0.096 \\
(0.559)\end{array}$ & $\begin{array}{l}-0.231 \\
(0.606)\end{array}$ & & & $\begin{array}{l}-0.189 \\
(0.511)\end{array}$ & $\begin{array}{l}-0.075 \\
(0.549)\end{array}$ & $\begin{array}{l}-0.262 \\
(0.594)\end{array}$ \\
\hline Temperature $\times$ Rich & $\begin{array}{c}0.219 \\
(0.210)\end{array}$ & $\begin{array}{c}0.202 \\
(0.232)\end{array}$ & $\begin{array}{c}0.243 \\
(0.241)\end{array}$ & $\begin{array}{c}0.293 \\
(0.238)\end{array}$ & $\begin{array}{c}0.392 \\
(0.255)\end{array}$ & $\begin{array}{c}0.208 \\
(0.212)\end{array}$ & $\begin{array}{c}0.197 \\
(0.234)\end{array}$ & $\begin{array}{c}0.237 \\
(0.243)\end{array}$ & $\begin{array}{c}0.272 \\
(0.240)\end{array}$ & $\begin{array}{c}0.383 \\
(0.260)\end{array}$ \\
\hline L1: Temperature $\times$ Rich & & $\begin{array}{c}0.047 \\
(0.268)\end{array}$ & $\begin{array}{c}0.074 \\
(0.251)\end{array}$ & $\begin{array}{c}0.094 \\
(0.252)\end{array}$ & $\begin{array}{c}0.093 \\
(0.268)\end{array}$ & & $\begin{array}{c}0.038 \\
(0.269)\end{array}$ & $\begin{array}{c}0.067 \\
(0.250)\end{array}$ & $\begin{array}{c}0.083 \\
(0.252)\end{array}$ & $\begin{array}{c}0.056 \\
(0.266)\end{array}$ \\
\hline L2: Temperature $\times$ Rich & & & $\begin{array}{c}0.062 \\
(0.190)\end{array}$ & $\begin{array}{c}0.115 \\
(0.195)\end{array}$ & $\begin{array}{c}0.043 \\
(0.209)\end{array}$ & & & $\begin{array}{c}0.064 \\
(0.190)\end{array}$ & $\begin{array}{c}0.143 \\
(0.194)\end{array}$ & $\begin{array}{c}0.098 \\
(0.209)\end{array}$ \\
\hline L3: Temperature $\times$ Rich & & & $\begin{array}{l}-0.019 \\
(0.197)\end{array}$ & $\begin{array}{c}0.120 \\
(0.186)\end{array}$ & $\begin{array}{c}0.203 \\
(0.198)\end{array}$ & & & $\begin{array}{l}-0.045 \\
(0.197)\end{array}$ & $\begin{array}{c}0.097 \\
(0.185)\end{array}$ & $\begin{array}{c}0.211 \\
(0.197)\end{array}$ \\
\hline Includes precipitation vars. & $\mathrm{NO}$ & $\mathrm{NO}$ & $\mathrm{NO}$ & $\mathrm{NO}$ & NO & YES & YES & YES & YES & YES \\
\hline Observations & 6014 & 6014 & 5905 & 5785 & 5449 & 6014 & 6014 & 5905 & 5785 & 5449 \\
\hline R-squared & 0.14 & 0.14 & 0.15 & 0.15 & 0.15 & 0.15 & 0.15 & 0.15 & 0.15 & 0.15 \\
\hline $\begin{array}{l}\text { Sum of all temp. coeff. } \\
\text { in poor countries } \\
\text { Sum of all temp. coeff. } \\
\text { in rich countries }\end{array}$ & $\begin{array}{l}-1.087 * * \\
(0.442) \\
-0.102 \\
(0.647)\end{array}$ & $\begin{array}{c}-1.304 * \\
(0.677) \\
0.219 \\
(0.210)\end{array}$ & $\begin{array}{l}-1.605^{* *} \\
(0.641) \\
0.249 \\
(0.268)\end{array}$ & $\begin{array}{l}-1.718^{* *} \\
(0.720) \\
0.361 \\
(0.331)\end{array}$ & $\begin{array}{l}-2.006^{* *} \\
(0.866) \\
0.184 \\
(0.455)\end{array}$ & $\begin{array}{l}-1.074 * * \\
(0.446) \\
0.208 \\
(0.212)\end{array}$ & $\begin{array}{c}-1.275^{*} \\
(0.689) \\
0.235 \\
(0.271)\end{array}$ & $\begin{array}{l}-1.576^{* *} \\
(0.651) \\
0.324 \\
(0.332)\end{array}$ & $\begin{array}{l}-1.662 * * \\
(0.737) \\
0.155 \\
(0.460)\end{array}$ & $\begin{array}{l}-1.946^{* *} \\
(0.881) \\
-0.147 \\
(0.654)\end{array}$ \\
\hline
\end{tabular}

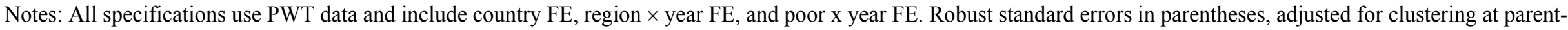

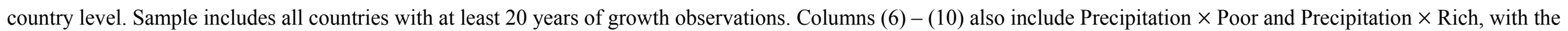
same number of lags as the temperature variables shown in the table. Columns (4) and (9) also include the $4^{\text {th }}$ and $5^{\text {th }}$ lags of Temperature $\times$ Poor, Temperature $\times$ Rich,

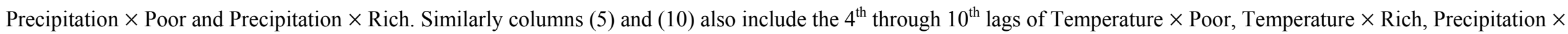

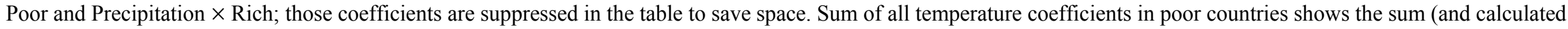

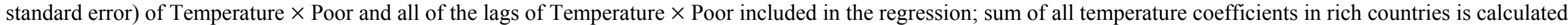
analogously.

$*$ significant at $10 \% ; * *$ significant at $5 \% ; * * *$ significant at $1 \%$ 
Table 4: Alternative specifications of panel results

\begin{tabular}{|c|c|c|c|c|c|c|c|c|c|c|}
\hline & $\begin{array}{c}(1) \\
\text { Baseline }\end{array}$ & $\begin{array}{c}(2) \\
\text { Country FE } \\
\text { and } \\
\text { Region } \times \text { Yr } \\
\text { FE only }\end{array}$ & $\begin{array}{c}\text { (3) } \\
\text { Country FE } \\
\text { and Year } \\
\text { FE only }\end{array}$ & $\begin{array}{c}(4) \\
\text { All FE and } \\
\text { country } \\
\text { specific } \\
\text { trends }\end{array}$ & $\begin{array}{c}(5) \\
\text { Balanced } \\
\text { sample: } \\
1971 \text { - 2003 }\end{array}$ & $\begin{array}{c}(6) \\
\text { Add } \\
\text { countries } \\
\text { with }<20 \\
\text { years of } \\
\text { data }\end{array}$ & $\begin{array}{c}(7) \\
\text { GDP data } \\
\text { from World } \\
\text { Devel. } \\
\text { Indicators }\end{array}$ & $\begin{array}{c}(8) \\
\text { Area- } \\
\text { weighted } \\
\text { climate data }\end{array}$ & $\begin{array}{c}(9) \\
\text { Sub- } \\
\text { Saharan } \\
\text { Africa } \\
\text { Only }\end{array}$ & $\begin{array}{c}(10) \\
\text { Sub- } \\
\text { Saharan } \\
\text { Africa } \\
\text { Excluded }\end{array}$ \\
\hline \multicolumn{11}{|l|}{ Panel A: Models with no lags } \\
\hline Temp. immediate effect - Poor & $\begin{array}{c}-1.074 * * \\
(0.446)\end{array}$ & $\begin{array}{c}-0.753 * * \\
(0.354)\end{array}$ & $\begin{array}{c}-0.986 * * * \\
(0.295)\end{array}$ & $\begin{array}{c}-1.009 * * \\
(0.438)\end{array}$ & $\begin{array}{c}-1.423 * * \\
(0.560)\end{array}$ & $\begin{array}{c}-0.892 * * \\
(0.381)\end{array}$ & $\begin{array}{c}-1.535 * * * \\
(0.397)\end{array}$ & $\begin{array}{c}-0.927 * \\
(0.501)\end{array}$ & $\begin{array}{c}-1.774 * * \\
(0.826)\end{array}$ & $\begin{array}{l}-0.404 \\
(0.402)\end{array}$ \\
\hline Temp. immediate effect - Rich & $\begin{array}{r}0.208 \\
(0.212)\end{array}$ & $\begin{array}{c}-0.026 \\
(0.203)\end{array}$ & $\begin{array}{l}-0.120 \\
(0.169)\end{array}$ & $\begin{array}{l}0.417^{*} \\
(0.238)\end{array}$ & $\begin{array}{l}0.473 * * \\
(0.228)\end{array}$ & $\begin{array}{l}0.611 * * \\
(0.271)\end{array}$ & $\begin{array}{c}0.306 \\
(0.250)\end{array}$ & $\begin{array}{c}0.333 \\
(0.225)\end{array}$ & $\begin{array}{l}-0.310 \\
(1.792)\end{array}$ & $\begin{array}{r}0.264 \\
(0.202)\end{array}$ \\
\hline Precip. immediate effect - Poor & $\begin{array}{r}0.030 \\
(0.065)\end{array}$ & $\begin{array}{c}0.008 \\
(0.065)\end{array}$ & $\begin{array}{c}0.007 \\
(0.061)\end{array}$ & $\begin{array}{c}0.032 \\
(0.067)\end{array}$ & $\begin{array}{r}0.013 \\
(0.065)\end{array}$ & $\begin{array}{l}-0.015 \\
(0.053)\end{array}$ & $\begin{array}{l}0.110^{* *} \\
(0.050)\end{array}$ & $\begin{array}{r}0.047 \\
(0.071)\end{array}$ & $\begin{array}{r}0.185 \\
(0.113)\end{array}$ & $\begin{array}{c}-0.057 \\
(0.074)\end{array}$ \\
\hline Precip. immediate effect - Rich & $\begin{array}{c}-0.072 * \\
(0.042)\end{array}$ & $\begin{array}{c}-0.060 \\
(0.041)\end{array}$ & $\begin{array}{l}-0.028 \\
(0.039)\end{array}$ & $\begin{array}{c}-0.093 * * \\
(0.045)\end{array}$ & $\begin{array}{c}-0.095^{* *} \\
(0.047)\end{array}$ & $\begin{array}{l}-0.039 \\
(0.051)\end{array}$ & $\begin{array}{c}-0.089 * * \\
(0.039)\end{array}$ & $\begin{array}{c}-0.074 \\
(0.047)\end{array}$ & $\begin{array}{c}0.210 \\
(0.209)\end{array}$ & $\begin{array}{c}-0.080 * * \\
(0.039)\end{array}$ \\
\hline Observations & 6014 & 6014 & 6014 & 6014 & 4290 & 6347 & 4927 & 6014 & 1809 & 4205 \\
\hline Panel B: Models with 5 lags & & & & & & & & & & \\
\hline Temp. cumulative effect - Poor & $\begin{array}{c}-1.662 * * \\
(0.737)\end{array}$ & $\begin{array}{c}-1.087 * \\
(0.643)\end{array}$ & $\begin{array}{l}-1.002 \\
(0.615)\end{array}$ & $\begin{array}{c}-1.362 \\
(1.088)\end{array}$ & $\begin{array}{c}-2.257^{* *} \\
(0.985)\end{array}$ & $\begin{array}{c}-1.300 * * \\
(0.575)\end{array}$ & $\begin{array}{c}-1.375 * * \\
(0.541)\end{array}$ & $\begin{array}{c}-1.592 * * \\
(0.721)\end{array}$ & $\begin{array}{l}-1.767 \\
(1.057)\end{array}$ & $\begin{array}{l}-1.231 \\
(1.316)\end{array}$ \\
\hline Temp. cumulative effect - Rich & $\begin{array}{c}0.155 \\
(0.460)\end{array}$ & $\begin{array}{c}-0.284 \\
(0.441)\end{array}$ & $\begin{array}{l}-0.481 \\
(0.422)\end{array}$ & $\begin{array}{c}0.445 \\
(0.704)\end{array}$ & $\begin{array}{c}0.257 \\
(0.593)\end{array}$ & $\begin{array}{r}0.336 \\
(0.541)\end{array}$ & $\begin{array}{c}0.118 \\
(0.381)\end{array}$ & $\begin{array}{c}0.256 \\
(0.459)\end{array}$ & $\begin{array}{c}1.636 \\
(2.748)\end{array}$ & $\begin{array}{c}0.031 \\
(0.453)\end{array}$ \\
\hline Precip. cumulative effect - Poor & $\begin{array}{c}0.128 \\
(0.146)\end{array}$ & $\begin{array}{c}0.061 \\
(0.142)\end{array}$ & $\begin{array}{c}0.039 \\
(0.138)\end{array}$ & $\begin{array}{c}0.184 \\
(0.175)\end{array}$ & $\begin{array}{c}0.131 \\
(0.172)\end{array}$ & $\begin{array}{c}-0.034 \\
(0.106)\end{array}$ & $\begin{array}{r}0.339 * \\
(0.197)\end{array}$ & $\begin{array}{c}0.141 \\
(0.146)\end{array}$ & $\begin{array}{c}0.683 \\
(0.412)\end{array}$ & $\begin{array}{c}-0.083 \\
(0.123)\end{array}$ \\
\hline Precip. cumulative effect - Rich & $\begin{array}{l}-0.127 \\
(0.085)\end{array}$ & $\begin{array}{c}-0.097 \\
(0.091)\end{array}$ & $\begin{array}{l}-0.057 \\
(0.079)\end{array}$ & $\begin{array}{c}-0.237 * * \\
(0.117)\end{array}$ & $\begin{array}{c}-0.191 * * \\
(0.078)\end{array}$ & $\begin{array}{c}0.022 \\
(0.143)\end{array}$ & $\begin{array}{c}-0.143 * \\
(0.078)\end{array}$ & $\begin{array}{l}-0.128 \\
(0.086)\end{array}$ & $\begin{array}{c}0.694 \\
(0.646)\end{array}$ & $\begin{array}{l}-0.124 * \\
(0.073)\end{array}$ \\
\hline Observations & 5785 & 5785 & 5785 & 5785 & 4290 & 6029 & 4919 & 5785 & 1785 & 4000 \\
\hline Panel C: Models with 10 lags & & & & & & & & & & \\
\hline Temp. cumulative effect - Poor & $\begin{array}{c}-1.946^{* *} \\
(0.881)\end{array}$ & $\begin{array}{c}-1.553 * \\
(0.811)\end{array}$ & $\begin{array}{c}-1.486 * * \\
(0.739)\end{array}$ & $\begin{array}{l}-1.655 \\
(1.460)\end{array}$ & $\begin{array}{c}-2.830 * * \\
(1.111)\end{array}$ & $\begin{array}{c}-1.633 * * \\
(0.697)\end{array}$ & $\begin{array}{l}-0.927 \\
(0.712)\end{array}$ & $\begin{array}{c}-1.811^{* *} \\
(0.872)\end{array}$ & $\begin{array}{l}-1.897 \\
(1.277)\end{array}$ & $\begin{array}{c}-1.444 \\
(1.397)\end{array}$ \\
\hline Temp. cumulative effect - Rich & $\begin{array}{l}-0.147 \\
(0.654)\end{array}$ & $\begin{array}{l}-0.299 \\
(0.667)\end{array}$ & $\begin{array}{l}-0.816 \\
(0.635)\end{array}$ & $\begin{array}{c}0.033 \\
(1.454)\end{array}$ & $\begin{array}{l}-0.109 \\
(0.824)\end{array}$ & $\begin{array}{c}0.051 \\
(0.842)\end{array}$ & $\begin{array}{r}0.180 \\
(0.490)\end{array}$ & $\begin{array}{l}-0.043 \\
(0.653)\end{array}$ & $\begin{array}{r}3.669 \\
(4.034)\end{array}$ & $\begin{array}{l}-0.343 \\
(0.639)\end{array}$ \\
\hline Precip. cumulative effect - Poor & $\begin{array}{r}0.107 \\
(0.171)\end{array}$ & $\begin{array}{c}0.029 \\
(0.170)\end{array}$ & $\begin{array}{l}-0.011 \\
(0.167)\end{array}$ & $\begin{array}{c}0.222 \\
(0.213)\end{array}$ & $\begin{array}{r}0.119 \\
(0.204)\end{array}$ & $\begin{array}{c}-0.071 \\
(0.137)\end{array}$ & $\begin{array}{l}0.576^{* *} \\
(0.225)\end{array}$ & $\begin{array}{c}0.122 \\
(0.168)\end{array}$ & $\begin{array}{c}0.516 \\
(0.463)\end{array}$ & $\begin{array}{c}-0.028 \\
(0.178)\end{array}$ \\
\hline Precip. cumulative effect - Rich & $\begin{array}{l}-0.112 \\
(0.109)\end{array}$ & $\begin{array}{c}-0.060 \\
(0.115)\end{array}$ & $\begin{array}{c}-0.033 \\
(0.107)\end{array}$ & $\begin{array}{c}-0.355^{* *} \\
(0.176)\end{array}$ & $\begin{array}{c}-0.213^{* *} \\
(0.107)\end{array}$ & $\begin{array}{c}0.061 \\
(0.220)\end{array}$ & $\begin{array}{l}-0.117 \\
(0.107)\end{array}$ & $\begin{array}{c}-0.115 \\
(0.111)\end{array}$ & $\begin{array}{c}0.472 \\
(0.841)\end{array}$ & $\begin{array}{c}-0.040 \\
(0.096)\end{array}$ \\
\hline Observations & 5449 & 5449 & 5449 & 5449 & 4290 & 5563 & 4909 & 5449 & 1737 & 3712 \\
\hline
\end{tabular}

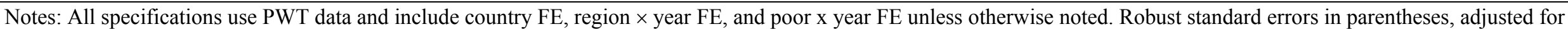

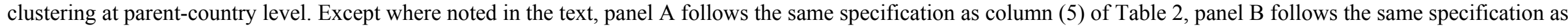

column (9) of Table 3, and panel C follows the same specification as column (10) of Table 3.

$*$ significant at $10 \% ; * *$ significant at $5 \% ; * * *$ significant at $1 \%$. 
Table 5: Components of Output Growth

\begin{tabular}{cccc} 
Panel A: Models with no lags & \multicolumn{3}{c}{ Dependent variable is: } \\
& $(1)$ & $(2)$ & $(3)$ \\
& Growth in & Growth in & Growth in \\
& Agriculture & Industrial Value & Investment \\
& Value Added & Added & \\
No lags & No lags & No lags \\
Temperature & $-2.367^{* * *}$ & $-2.443^{* *}$ & $-2.991^{* *}$ \\
Immediate effect - Poor & $(0.816)$ & $(0.958)$ & $(1.189)$ \\
& -0.340 & 0.410 & -0.103 \\
Immediate effect - Rich & $(0.512)$ & $(0.376)$ & $(0.470)$ \\
& & & \\
Precipitation & $0.242^{* *}$ & $0.295^{* *}$ & 0.040 \\
Immediate effect - Poor & $(0.117)$ & $(0.133)$ & $(0.170)$ \\
& $0.138^{*}$ & -0.050 & $-0.425^{* * *}$ \\
Immediate effect - Rich & $(0.077)$ & $(0.071)$ & $(0.109)$ \\
& 3812 & 3812 & 6014 \\
\hline \hline
\end{tabular}

Panel B: Models with lags

\begin{tabular}{|c|c|c|c|c|c|c|c|c|c|}
\hline & \multicolumn{9}{|c|}{ "Dependent variable is: } \\
\hline & \multicolumn{3}{|c|}{ Growth in Agriculture Value Added } & \multicolumn{3}{|c|}{ Growth in Industrial Value Added } & \multicolumn{3}{|c|}{ Growth in Investment } \\
\hline Temperature & $1 \mathrm{Lag}$ & 5 Lags & 10 Lags & $1 \mathrm{Lag}$ & 5 Lags & 10 Lags & $1 \mathrm{Lag}$ & 5 Lags & 10 Lags \\
\hline \multirow{2}{*}{ Cumulative effect - Poor } & -1.078 & -1.440 & $-1.800^{*}$ & $-2.842 * *$ & -2.076 & -2.410 & -2.078 & -2.071 & -2.118 \\
\hline & $(0.777)$ & $(0.880)$ & $(1.044)$ & $(1.235)$ & $(1.672)$ & $(2.129)$ & $(1.325)$ & $(2.070)$ & $(2.896)$ \\
\hline \multirow[t]{2}{*}{ Cumulative effect - Rich } & 0.419 & 0.346 & 0.662 & 0.517 & 0.473 & 0.852 & -0.401 & -1.194 & -1.312 \\
\hline & $(0.538)$ & $(0.588)$ & $(0.717)$ & $(0.455)$ & $(0.565)$ & $(0.762)$ & $(0.534)$ & $(0.817)$ & $(1.112)$ \\
\hline \multirow[t]{2}{*}{ Immediate effect - Poor } & $-3.081 * * *$ & $-2.947 * * *$ & $-3.044 * * *$ & $-2.182 * *$ & $-2.350 * *$ & $-2.532 * *$ & $-3.512 * *$ & $-3.943 * * *$ & $-3.930 * * *$ \\
\hline & $(1.056)$ & $(1.008)$ & $(1.019)$ & $(0.930)$ & $(0.999)$ & $(1.000)$ & $(1.417)$ & $(1.338)$ & $(1.386)$ \\
\hline \multirow[t]{2}{*}{ Immediate effect - Rich } & -0.791 & -0.731 & -0.861 & 0.369 & 0.323 & 0.292 & 0.091 & 0.316 & 0.303 \\
\hline & $(0.640)$ & $(0.625)$ & $(0.641)$ & $(0.372)$ & $(0.381)$ & $(0.389)$ & $(0.600)$ & $(0.638)$ & $(0.719)$ \\
\hline \multicolumn{10}{|l|}{ Precipitation } \\
\hline \multirow[t]{2}{*}{ Cumulative effect - Poor } & 0.153 & 0.118 & 0.087 & $0.416^{* * *}$ & $0.407 * *$ & 0.390 & 0.196 & -0.076 & -0.030 \\
\hline & $(0.105)$ & $(0.129)$ & $(0.169)$ & $(0.132)$ & $(0.166)$ & $(0.301)$ & $(0.192)$ & $(0.269)$ & $(0.305)$ \\
\hline \multirow[t]{2}{*}{ Cumulative effect - Rich } & $0.174 * *$ & $0.392 * * *$ & $0.495 * *$ & -0.118 & -0.259 & -0.147 & $-0.456 * * *$ & -0.236 & $-0.512 *$ \\
\hline & $(0.078)$ & $(0.095)$ & $(0.197)$ & $(0.108)$ & $(0.197)$ & $(0.252)$ & $(0.128)$ & $(0.211)$ & $(0.297)$ \\
\hline \multirow[t]{2}{*}{ Immediate effect - Poor } & $0.270 * *$ & $0.309 * *$ & $0.331 * *$ & 0.238 & 0.138 & 0.098 & -0.037 & 0.032 & 0.000 \\
\hline & $(0.127)$ & $(0.130)$ & $(0.132)$ & $(0.145)$ & $(0.125)$ & $(0.117)$ & $(0.209)$ & $(0.209)$ & $(0.209)$ \\
\hline \multirow[t]{2}{*}{ Immediate effect - Rich } & 0.136 & 0.137 & 0.149 & -0.030 & -0.038 & -0.027 & $-0.405 * * *$ & $-0.454 * * *$ & $-0.445 * * *$ \\
\hline & $(0.091)$ & $(0.093)$ & $(0.093)$ & $(0.068)$ & $(0.071)$ & $(0.072)$ & $(0.123)$ & $(0.135)$ & $(0.146)$ \\
\hline Observations & 3812 & 3804 & 3794 & 3812 & 3804 & 3794 & 6014 & 5785 & 5449 \\
\hline
\end{tabular}

Notes: Growth in agriculture value-added and industrial value-added are from the World Development Indicators; growth in investment is from the Penn World Tables. All

specifications include country FE, region $\times$ year FE, and poor x year FE. Robust standard errors in parentheses, adjusted for clustering at parent-country level. Sample includes all countries with at least 20 years of PWT growth observations (i.e., the same set of countries considered in the previous tables.) 
Table 6: Political economy effects

\begin{tabular}{|c|c|c|c|c|c|c|c|}
\hline & \multirow[b]{3}{*}{$\begin{array}{l}\text { Any change } \\
\text { in POLITY } \\
\text { score }\end{array}$} & \multirow{3}{*}{$\begin{array}{l}\text { POLITY } \\
\text { interregnum } \\
\text { period }\end{array}$} & \multirow{3}{*}{$\begin{array}{l}\text { (3) } \\
\text { Political Stability } \\
\text { Leader } \\
\text { transition }\end{array}$} & (4) & (5) & (6) & (7) \\
\hline & & & & \multirow[b]{2}{*}{$\begin{array}{l}\text { Regular } \\
\text { leader } \\
\text { transition }\end{array}$} & \multirow[b]{2}{*}{$\begin{array}{l}\text { Irregular } \\
\text { leader } \\
\text { transition }\end{array}$} & \multicolumn{2}{|c|}{ Conflict } \\
\hline & & & & & & $\begin{array}{l}\text { Start of new } \\
\text { conflicts } \\
\text { (conditional } \\
\text { on conflict = } \\
0 \text { in } t-1 \text { ) }\end{array}$ & $\begin{array}{l}\text { End of } \\
\text { conflicts } \\
\text { (conditional } \\
\text { on conflict }> \\
0 \text { in } t-1 \text { ) } \\
\end{array}$ \\
\hline \multirow[t]{2}{*}{ Temperature } & -0.008 & $-0.015 * *$ & -0.003 & -0.002 & -0.001 & -0.005 & 0.019 \\
\hline & $(0.009)$ & $(0.007)$ & $(0.013)$ & $(0.013)$ & $(0.005)$ & $(0.005)$ & $(0.051)$ \\
\hline \multirow[t]{2}{*}{ Temperature X Poor } & $0.031 *$ & $0.037 * *$ & $0.040^{*}$ & $(0.001)$ & $0.041 * * *$ & 0.014 & $(0.017)$ \\
\hline & $(0.018)$ & $(0.018)$ & $(0.022)$ & $(0.017)$ & $(0.013)$ & $(0.012)$ & $(0.056)$ \\
\hline \multirow{2}{*}{ Precipitation } & 0.000 & 0.001 & 0.002 & 0.002 & 0.000 & 0.001 & 0.009 \\
\hline & $(0.003)$ & $(0.001)$ & $(0.002)$ & $(0.002)$ & $(0.001)$ & $(0.001)$ & $(0.015)$ \\
\hline \multirow[t]{2}{*}{ Precipitation X Poor } & $-0.010 * *$ & $(0.005)$ & $-0.006^{*}$ & $-0.006^{*}$ & 0.000 & -0.003 & -0.015 \\
\hline & $(0.004)$ & $(0.003)$ & $(0.004)$ & $(0.003)$ & $(0.002)$ & $(0.002)$ & $(0.016)$ \\
\hline Obs. & 5804 & 5804 & 7143 & 7143 & 7143 & 6087 & 966 \\
\hline R-squared & 0.14 & 0.21 & 0.18 & 0.2 & 0.11 & 0.09 & 0.43 \\
\hline Temperature effect in poor & 0.023 & 0.023 & $0.037 * *$ & -0.002 & $0.039 * * *$ & 0.009 & 0.002 \\
\hline Countries & $(0.016)$ & $(0.018)$ & $(0.018)$ & $(0.010)$ & $(0.012)$ & $(0.011)$ & $(0.032)$ \\
\hline Precipitation effect in poor & $-0.010 * * *$ & -0.005 & -0.004 & -0.004 & 0.000 & -0.001 & -0.006 \\
\hline Countries & $(0.004)$ & $(0.003)$ & $(0.003)$ & $(0.002)$ & $(0.001)$ & $(0.001)$ & $(0.006)$ \\
\hline
\end{tabular}

Notes: Columns (1) and (2) use data from the POLITY IV dataset; columns (3), (4), and (5) use data from the Archigos dataset; and columns (6) and (7) use data from the PRIO dataset. Columns (1) - (5) include country FE, region $\times$ year FE, and poor x year FE; columns (6) and (7) include country FE and year FE. Robust standard errors in parentheses, adjusted for clustering at parent-country level. Sample includes all countries with at least 20 years of PWT growth observations (i.e., the same set of countries considered in the previous tables.)

* significant at $10 \% ; * *$ significant at $5 \% ; * * *$ significant at $1 \%$ 
Table 7: Changes in growth and climate in the medium-run

\begin{tabular}{|c|c|c|c|c|c|c|c|c|c|}
\hline \multicolumn{10}{|c|}{ Dependent variable: change in mean growth rate } \\
\hline & $(1)$ & (2) & (3) & $(4)$ & (5) & (6) & (7) & $(8)$ & (9) \\
\hline & $\begin{array}{l}\text { Baseline } \\
\text { Sample }\end{array}$ & & \multicolumn{4}{|c|}{ Alternative comparison years } & Africa Only & $\begin{array}{l}\text { Excluding } \\
\text { Africa }\end{array}$ & $\begin{array}{l}\text { WDI } \\
\text { data }\end{array}$ \\
\hline Change in Temperature & 1.499 & $1.900 *$ & 1.014 & -0.544 & $1.677^{*}$ & 0.854 & -3.022 & $2.084^{*}$ & 1.403 \\
\hline & $(0.978)$ & $(1.023)$ & $(0.732)$ & $(0.778)$ & $(0.974)$ & $(1.050)$ & $(1.811)$ & $(1.064)$ & $(0.891)$ \\
\hline Change in Temperature & $-4.700 * * *$ & $-5.145 * * *$ & $-4.377 * * *$ & -1.744 & $-4.194 * *$ & -2.168 & 0.081 & $-4.686 * *$ & $-3.696 * *$ \\
\hline X Poor Country & $(1.584)$ & $(1.619)$ & $(1.542)$ & $(1.710)$ & $(1.780)$ & $(2.164)$ & $(2.751)$ & $(2.229)$ & $(1.463)$ \\
\hline Change in Precipitation & 0.097 & 0.130 & 0.051 & -0.014 & 0.016 & -0.010 & 0.654 & 0.145 & -0.066 \\
\hline & $(0.127)$ & $(0.148)$ & $(0.117)$ & $(0.256)$ & $(0.121)$ & $(0.168)$ & $(1.463)$ & $(0.159)$ & $(0.108)$ \\
\hline Change in Precipitation & -0.157 & -0.268 & -0.164 & 0.121 & 0.046 & 0.114 & -0.155 & -0.428 & 0.100 \\
\hline X Poor Country & $(0.255)$ & $(0.252)$ & $(0.235)$ & $(0.499)$ & $(0.244)$ & $(0.265)$ & $(1.586)$ & $(0.270)$ & $(0.203)$ \\
\hline Region FE & No & Yes & Yes & Yes & Yes & Yes & No & Yes & Yes \\
\hline Poor Country Dummy & Yes & Yes & Yes & Yes & Yes & Yes & Yes & Yes & Yes \\
\hline Early Period & 1970-1985 & 1970-1985 & $1970-1987$ & $1961-1970$ & $1971-1980$ & $\begin{array}{c}1981- \\
1990\end{array}$ & $1970-1985$ & $1970-1985$ & $1970-1985$ \\
\hline Late Period & $1986-2000$ & $1986-2000$ & $1988-2003$ & $1991-2000$ & $1991-2000$ & $\begin{array}{c}1991- \\
2000\end{array}$ & $1986-2000$ & $1986-2000$ & $1986-2000$ \\
\hline Observations & 134 & 134 & 134 & 93 & 134 & 134 & 41 & 93 & 121 \\
\hline R-squared & 0.07 & 0.16 & 0.13 & 0.12 & 0.10 & 0.13 & 0.09 & 0.23 & 0.13 \\
\hline Temperature effect on poor & $-3.201 * *$ & $-3.245^{* *}$ & $-3.363 * *$ & -2.289 & -2.518 & -1.314 & -2.942 & -2.602 & $-2.294 *$ \\
\hline Countries & $(1.245)$ & $(1.348)$ & $(1.426)$ & $(1.523)$ & $(1.592)$ & $(2.037)$ & $(2.071)$ & $(2.108)$ & $(1.188)$ \\
\hline Precipitation effect on poor & -0.059 & -0.137 & -0.114 & 0.107 & 0.062 & 0.105 & 0.499 & -0.284 & 0.035 \\
\hline Countries & $(0.221)$ & $(0.207)$ & $(0.203)$ & $(0.418)$ & $(0.219)$ & $(0.212)$ & $(0.614)$ & $(0.215)$ & $(0.168)$ \\
\hline
\end{tabular}


Table 8: Illustrated Growth Impacts of Temperature Change through 2099, Compared to Baseline of No Temperature Change

\begin{tabular}{|c|c|c|c|c|}
\hline & \multicolumn{4}{|c|}{ Time Horizon for Adjustment } \\
\hline & 10 years & 25 years & 50 years & $\begin{array}{c}\text { No } \\
\text { adaptation }\end{array}$ \\
\hline \multicolumn{5}{|l|}{ Poor countries } \\
\hline Median growth rate effect & $-0.6 \%$ & $-1.4 \%$ & $-2.3 \%$ & $-2.9 \%$ \\
\hline \multicolumn{5}{|l|}{ World Economy } \\
\hline World GDP loss & $-0.2 \%$ & $-0.3 \%$ & $-0.3 \%$ & $-0.3 \%$ \\
\hline World 75/25 Inequality & $+88 \%$ & $+340 \%$ & $+1100 \%$ & $+2100 \%$ \\
\hline \multicolumn{5}{|l|}{ Lower bound income } \\
\hline Number of countries & 13 & 21 & 37 & 41 \\
\hline
\end{tabular}

Notes: Projections are made for 122 countries under the A2 emissions scenario. The 10-lag model of column (1) in Table 4 is used for the estimated growth effect in poor countries. Zero effect is assumed for rich countries, given the statistical insignificance of the historical estimates in rich countries. The lower bound income is taken as the $1^{\text {st }}$ percentile of income witnessed historically in the Penn World Tables. See further discussion in text. 
Figure 1: Time trends in world average temperature and precipitation

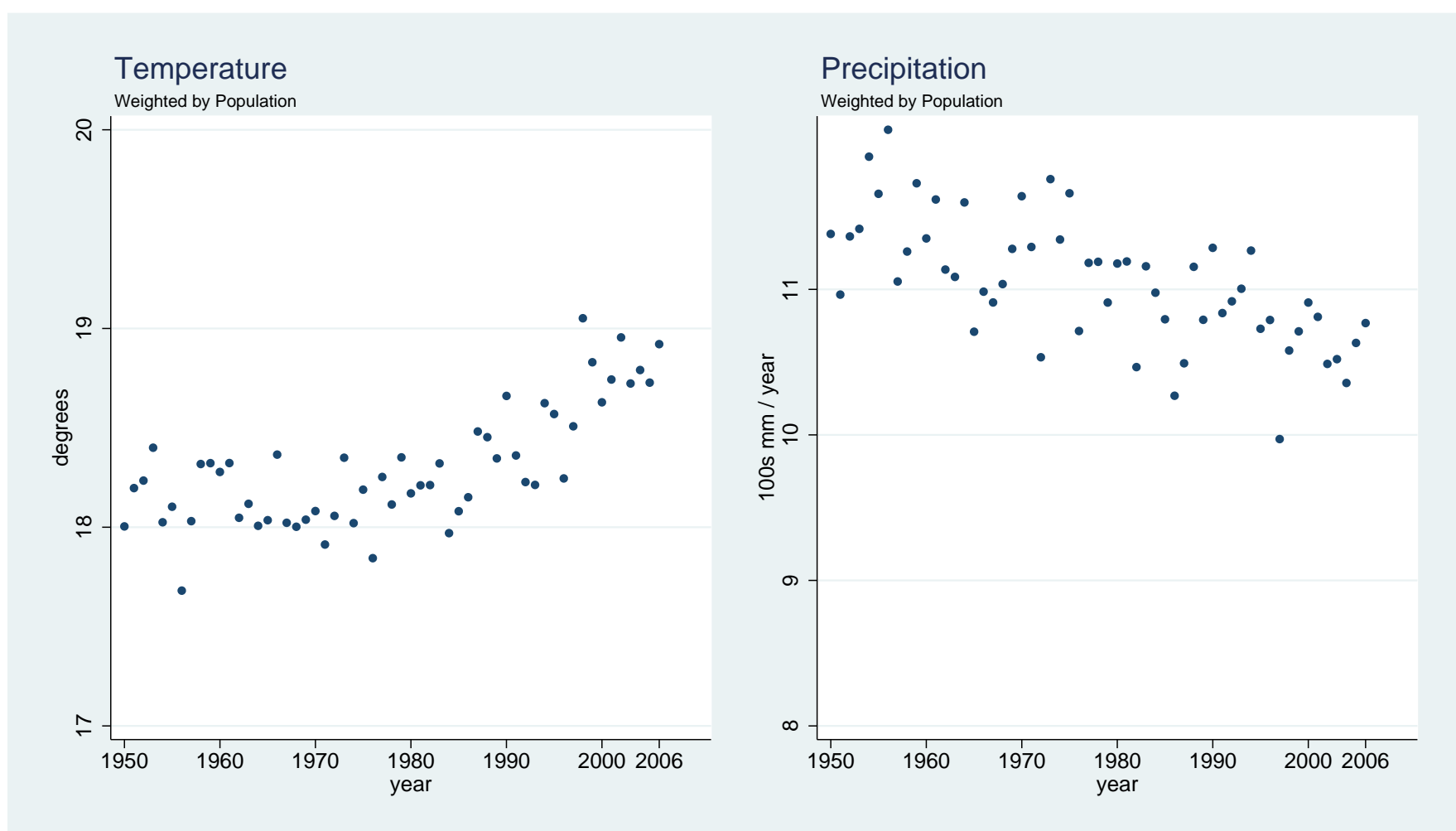

Notes: Calculations are done using 1990 population weights. 


\section{Figure 2: Changes and variability in climate}

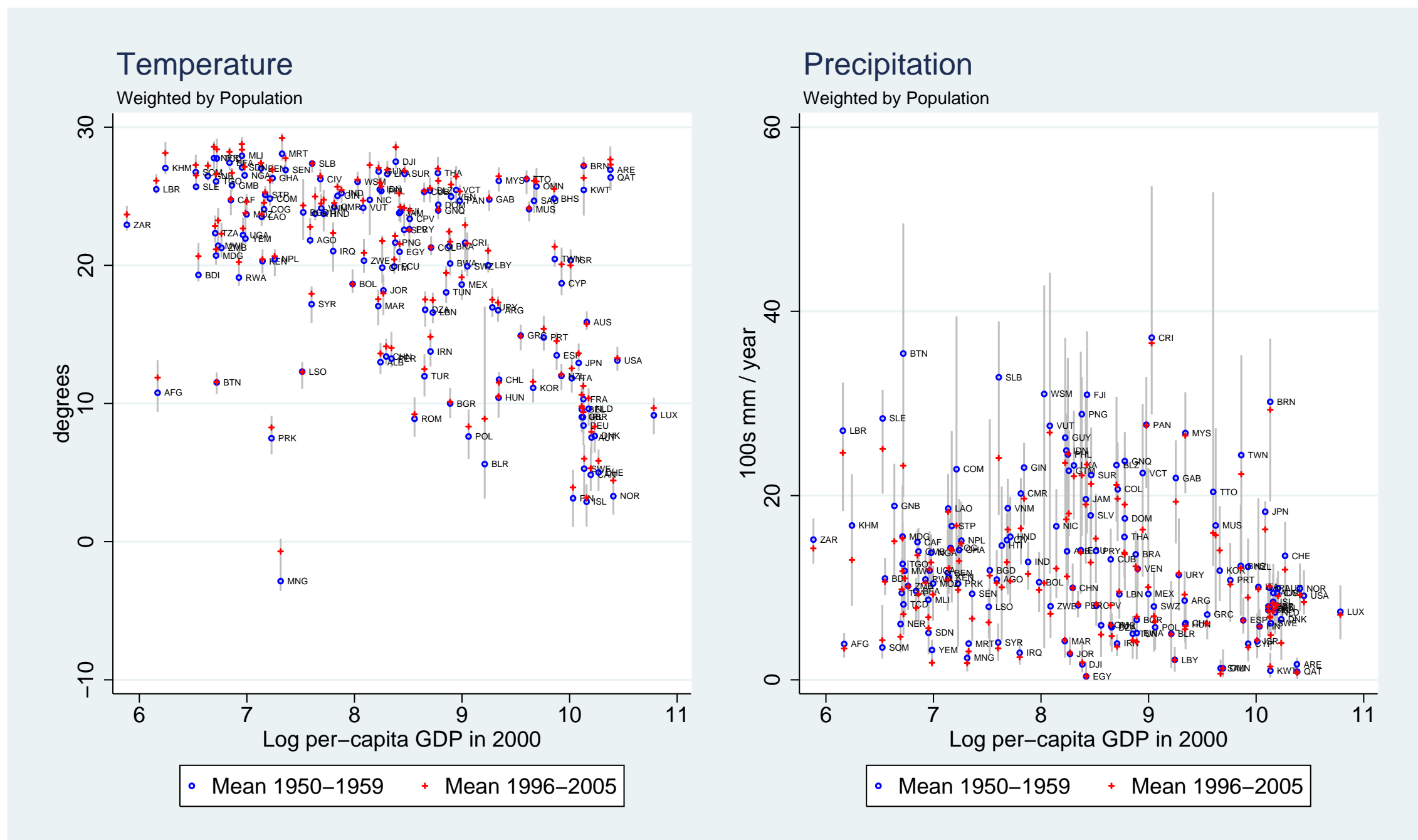

Notes: These graphs present data on each country's temperature (left graph) and precipitation (right graph), potted against per-capita PPP GDP from the Penn World Tables in the year 2000. For each country, the circle symbols represent the mean level of temperature / precipitation in the first decade of our sample (1950-1959), the plus symbols represent the mean level of temperature / precipitation in the last decade of our sample (1996-2005), and the gray lines indicate the range of annual temperature / precipitation levels we observe for that country during our sample period. Country averages are calculated using population weights, as discussed in the text. 


\section{Appendix Table 1: Dynamic Panel Estimates}

Model:

No lagged growth effects

$\begin{array}{lll}-1.275^{*} & -1.662 * * & -1.946 * * \\ (0.681) & (0.728) & (0.869)\end{array}$

1 lag of growth, OLS

$-1.397^{*}$

$-1.794 * *$

$-2.058^{* *}$

(0.726)

$(0.748)$

$(0.894)$

$p$ lags of growth, OLS

$\begin{array}{ll}-1.780 * * & -2.382 * * * \\ (0.807) & (0.877)\end{array}$

$p$ lags of growth, IV

$\begin{array}{lll}-1.745 & -1.275 & -2.004^{* *} \\ (1.174) & (1.053) & (0.806)\end{array}$

Notes: Each reported coefficient is the estimated growth effect of temperature in poor countries, calculated using equation (A1.6), from a separate regression of the form in equation (A1.5). The underlying equations include country fixed effects, region $\times$ time fixed effects, poor $x$ year FE, temperature and precipitation interacted with poor/rich dummies, and the number of lags of temperature and precipitation shown in the column. Robust standard errors are in parentheses, adjusted for clustering at the country level. Note that the estimates in the first row exactly replicate the 'sum of all temp. coefficients in poor countries' shown in columns (7), (9), and (10) of Table 3. In row 2, the equation includes 1 lag of growth as an independent variable. In row 3 , the equation includes 4 lags of growth in column (2) and 9 lags of growth in column (3). In row 4 , the equation includes 4 lags of growth in column (2), with the $1^{\text {st }}$ lag instrumented using the $5^{\text {th }}$ lag, and 9 lags of growth in column (3), with the $1^{\text {st }}$ lag instrumented using the $10^{\text {th }}$ lag. 